FACULDADE DE ZOOTECNIA E ENGENHARIA DE ALIMENTOS

ROBSON HUMBERTO ROSA

EXTRAÇÃO DE DITERPENOS DE CAFÉ VERDE: MODELAGEM FENOMENOLÓGICA E CARACTERIZAÇÃO DE PARÂMETROS VIA MÉTODO LATTICE BOLTZMANN 
ROBSON HUMBERTO ROSA

\section{EXTRAÇÃO DE DITERPENOS DE CAFÉ VERDE: MODELAGEM FENOMENOLÓGICA E CARACTERIZAÇÃO DE PARÂMETROS VIA MÉTODO LATTICE BOLTZMANN}

(Versão Corrigida)

Dissertação apresentada à Faculdade de Zootecnia e Engenharia de Alimentos da Universidade de São Paulo, como parte dos requisitos para obtenção do título de mestre em Engenharia e Ciência dos Materiais.

Área de Concentração: Desenvolvimento, Caracterização e Aplicação de Materiais Voltados à Agroindústria.

Orientador: Prof. Dr. José Antonio Rabi.

Pirassununga

2014 
Dados Internacionais de Catalogação na Publicação

Serviço de Biblioteca e Informação da Faculdade de Zootecnia e Engenharia de Alimentos da Universidade de São Paulo

Rosa, Robson Humberto

Extração de diterpenos de café verde: modelagem

fenomenológica e caracterização de parâmetros via método

lattice Boltzmann / Robson Humberto Rosa. -

Pirassununga, 2014.

$78 \mathrm{f}$.

Dissertação (Mestrado) -- Faculdade de Zootecnia e

Engenharia de Alimentos - Universidade de São Paulo.

Departamento de Engenharia de Biossistemas.

Área de Concentração: Desenvolvimento, Caracterização

e Aplicação de Materiais Voltados à Agroindústria.

Orientador: Prof. Dr. José Antonio Rabi.

1. Modelagem fenomenológica 2. Simulação numérica 3. Método lattice Boltzmann 4. Extração com fluido pressurizado 5. Café verde. I. Título. 


\section{DEDICATÓRIA}

Aos meus avós, Alaor e Orlandina, meus pais, Carlos e Celina, e meus irmãos, Kris, Olívia e Rodney, que sempre me incentivaram a persistir na busca dos meus ideais. 


\section{AGRADECIMENTOS}

Agradeço a Deus, por ter me dado sabedoria e paciência para chegar até aqui, pois em meio às dificuldades sempre esteve comigo.

À minha família, meus pais, irmãos, tios e primos, que sempre me incentivam e apoiam nos momentos bons e ruins.

Aos professores do programa de pós-graduação em Engenharia e Ciência dos Materiais, pelos ensinamentos em salas de aula e nos laboratórios de pesquisas, tanto para minha formação acadêmica e profissional como pessoal.

Aos alunos do Laboratório de Física Aplicada e Computacional, aos professores Dr. Ernane, Dr. Adriano Tech, Dra. Ana Carolina e ao Ms. Gustavo von Atzingen.

Às bibliotecárias, Vanessa, Bernadete e Patrícia pela colaboração na revisão bibliográfica e formatação desta dissertação.

Às secretárias do programa de pós-graduação, Layla, Stefani e Alecsandra pelo empenho e auxilio nos quesitos documentação acadêmica.

Ao meu orientador professor Dr. José Antonio Rabi pelas instruções, orientações, apoio e, principalmente, pela confiança. 
"Se enxerguei mais longe, foi por estar de pé sobre os ombros de gigantes" 


\section{RESUMO}

ROSA, R.H. Extração de diterpenos de café verde: modelagem fenomenológica e caracterização de parâmetros via método lattice Boltzmann. 2014. 78 f. Dissertação (Mestrado) - Faculdade de Zootecnia e Engenharia de Alimentos, Universidade de São Paulo, Pirassununga, 2014.

Por meio do método lattice Boltzmann (LBM), este projeto de pesquisa propõe a simulação computacional da extração dos compostos diterpênicos do café verde em sistemas com fluido pressurizado. Para isso foi adotado um modelo fenomenológico dinâmico e de primeira ordem quanto à dependência espacial. Usando a rede D1Q2, o LBM foi implementado com duas funções de distribuição de partículas, acompanhadas das respectivas funções de distribuição de equilíbrio. Cada função refere-se à concentração em uma dada fase (sólida e fluida). A previsão das curvas de rendimento pressupõe o conhecimento dos parâmetros do processo, tais como a difusividade mássica interna (intrapartícula), o coeficiente de partição volumétrica e a difusividade mássica axial. Para o devido ajuste destes parâmetros contra dados experimentais, foi desenvolvido um código computacional utilizando a técnica de gradiente descendente. Resultados numéricos das simulações foram comparados com dados experimentais e mostraram-se satisfatórios. Adicionalmente, foi realizada a análise da influência dos parâmetros supracitados mediante a criação de uma interface gráfica amigável para o código computacional original. Este projeto de pesquisa, além de fomentar a agregação de valor ao café, desenvolveu competências em modelagem e simulação de processos de extração de espécies químicas a partir de métodos numéricos.

Palavras-chave: modelagem fenomenológica, simulação numérica, método lattice Boltzmann, extração com fluido pressurizado, café verde. 


\begin{abstract}
ROSA, R.H. Diterpene extraction of green coffee beans: phenomenological modeling and characterization of parameters by lattice Boltzmann method. 2014. 76 f. Dissertation (Master Degree) - College of Animal Science and Food Engineering, São Paulo University, Pirassununga, 2014.
\end{abstract}

Using the lattice Boltzmann method (LBM), this research project proposes a computer simulation of diterpene compounds extraction from green coffee beans in high pressure fluid systems. In order to do so, a dynamic phenomenological model with first-order spatial dependence was adopted. LBM was implemented on D1Q2 lattice, using two particle distribution functions, followed by the respective equilibrium distribution functions. Each function refers to the extract concentration in each phase, namely solid and fluid. Prediction of extract yield curves relies on process parameters such as internal (i.e., intraparticle) mass diffusivity, volumetric partition coefficient and axial mass diffusivity. Values of aforesaid parameters were fitted against experimental data via descendent gradient technique coupled to the LBM computer code and numerically simulated result were consistent. Besides modeling and simulation, this project performed the influence analysis of those process parameters. To this end, a user-friendly graphical interface for the original computer code was created. While fostering value to be added to coffee, this research project develops skills in modeling and simulation of chemical species extraction through numerical methods.

Key words: phenomenological modeling, numerical simulation, lattice Boltzmann method, pressurized fluid extraction, green coffee beans. 


\section{LISTA DE ILUSTRAÇÕES}

Figura 1. Grãos de café verde arábica (esquerda) e robusta (direita). Fonte: TSUKUI et al., 2013.

Figura 2. Estrutura dos principais diterpenos do café verde (caveol e cafestol). Fonte: Adaptação de RINCON, 2011.

Figura 3. Espectro de absorção (190nm a 800nm) de caveol (A) e cafestol (B), obtidos com padrão comercial. Fonte: adaptado de DIAS, 2009

Figura 4. (a) Leito fixo em sistema de coordenadas cilíndricas; (b) velocidade intersticial

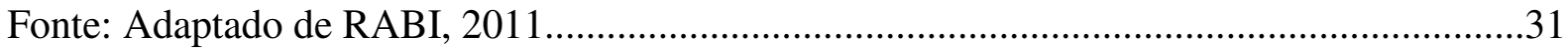

Figura 5. Etapas da simulação computacional via LBM......................................................36

Figura 6. Rede D1Q2 para simulação via LBM. Fonte: RABI, 2011.....................................39

Figura 7. a) Rede D2Q4 ou D2Q5, b) D2Q8 ou D2Q9. Fonte: RABI, 2011..........................39

Figura 8. a) Rede D3Q14 ou D3Q15, b) D3Q18 ou D3Q19. Fonte: RABI, 2011..................39

Figura 9. Fluxograma da simulação numérica via LBM.....................................................46

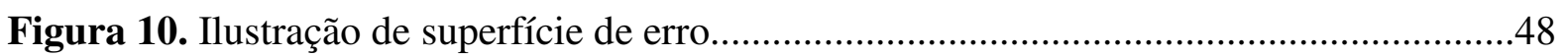

Figura 11. Fluxograma: ajuste dos parâmetros via gradiente descendente............................50

Figura 12. Extração de cafestol: curvas de concentração de extrato na fase fluida saindo do leito, simuladas via LBM.

Figura 13. Extração de caveol: curvas de concentração de extrato na fase fluida saindo do leito, simuladas via LBM. .58

Figura 14. Extração de cafestol: comparação entre as curvas de rendimento simuladas via LBM e os resultados experimentais.

Figura 15. Extração de caveol: comparação entre as curvas de rendimento simuladas via LBM e os resultados experimentais

Figura 16. Análise de sensibilidade dos parâmetros: difusividade intrapartícula. 61

Figura 17. Análise de sensibilidade dos parâmetros: coeficiente de partição volumétrica. ....62

Figura 18. Análise de sensibilidade dos parâmetros: difusividade mássica axial. .63 


\section{LISTA DE TABELAS}

Tabela 1. Cinéticas da extração de cafestol via PFE............................................................28

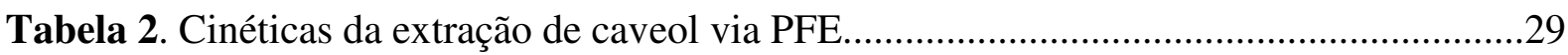

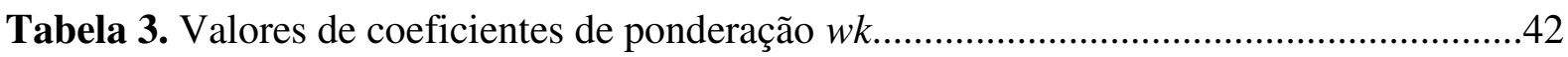

Tabela 4. Classificação dos parâmetros de simulação via LBM..............................................51

Tabela 5. Medidas experimentais: densidades dos grãos de café verde.................................53

Tabela 6. Valores dos coeficientes de formato das partículas................................................53

Tabela 7. Medida experimental: raio médio dos grãos de café verde ....................................53

Tabela 8. Medidas experimentais: massa de extrato na fase sólida......................................54

Tabela 9. Parâmetros independentes da temperatura...........................................................55

Tabela 10. Extração de caveol: parâmetros do processo ajustáveis.......................................55

Tabela 11. Extração de cafestol: parâmetros do processo ajustáveis.....................................56

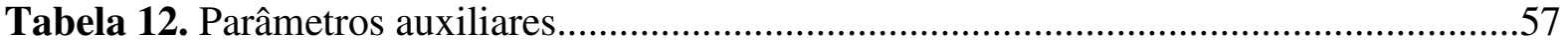




\section{NOMENCLATURA}

\section{Símbolos latinos}

$\begin{array}{ll}A & \text { Área da seção transversal }\left(\mathrm{m}^{2}\right) \\ c_{\mathrm{S}} & \text { Velocidade do som na rede fictícia }\left(\mathrm{m} \cdot \mathrm{s}^{-1}\right) \\ D & \text { Difusividade mássica axial }\left(\mathrm{m}^{2} \cdot \mathrm{s}^{-1}\right) \\ D i & \text { Difusividade mássica interna }\left(\mathrm{m}^{2} \cdot \mathrm{s}^{-1}\right) \\ f & \text { Função de distribuição de partículas }(\text { adimensional }) \\ k_{P} & \text { Coeficiente de partição volumétrica }\left(\mathrm{m}^{3}-\mathrm{sólido} / \mathrm{m}^{3}-\text { fluido }\right) \\ L & \text { Comprimento do leito }(\mathrm{m}) \\ l_{p} & \text { Comprimento característico da partícula }(\mathrm{m}) \\ m & \text { Massa da amostra }(\mathrm{kg}) \\ \mathrm{R} & \text { Raio interno do leito }(\mathrm{m}) \\ r & \text { Raio médio da partícula }(\mathrm{m}) \\ \dot{V} & \text { Vazão volumétrica de solvente }\left(\mathrm{m}^{3} \cdot \mathrm{s}^{-1}\right) \\ v & \text { Velocidade intersticial }\left(\mathrm{m} \cdot \mathrm{s}^{-1}\right) \\ t & \text { Tempo (s) } \\ \Delta t & \text { Intervalo de tempo }(\mathrm{s})\end{array}$

\section{Símbolos gregos}

$\varepsilon \quad$ Porosidade do leito (adimensional)

$\mu_{\mathrm{p}} \quad$ Coeficiente de formato da partícula (adimensional)

$\Psi \quad$ Concentração de extrato na fase sólida (adimensional)

$\rho \quad$ Densidade $\left(\mathrm{kg} \cdot \mathrm{m}^{-3}\right)$

$\Omega \quad$ Operador de colisão $\left(\mathrm{s}^{-1}\right)$

$\omega \quad$ Parâmetro de relaxação (adimensional)

\section{Subscritos e sobrescritos}

apar Relativo à densidade aparente

eq Relativo ao valor de equilíbrio da função de distribuição de partículas

extrato Relativo à massa extraída

i Relativo ao tempo de difusão intrapartícula

max Relativo à máxima concentração de extrato na fase sólida 
real Relativo à densidade

relax Relativo ao tempo de relaxação

total Relativo à massa total no leito

\section{Siglas}
ASE Extração com solvente acelerado
BGK Aproximação Bathnagar-Gross-Krook
EDP Equações diferenciais parciais
LBM Método lattice Boltzmann
PFE Extração com fluido pressurizado
SFE Extração com fluido supercrítico 


\section{SUMÁRIO}

1 INTRODUÇÃ

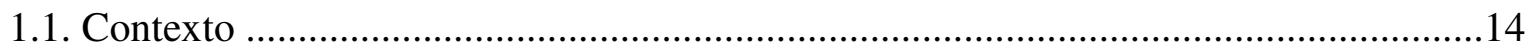

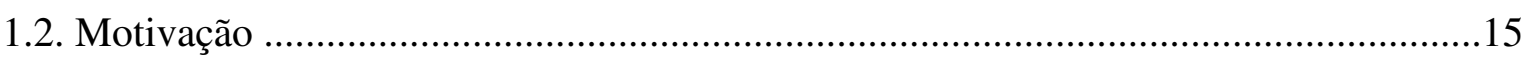

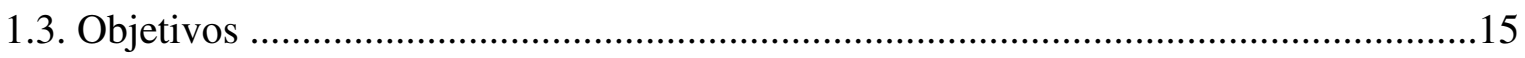

1.4. Organização do texto ……………………………………………………………16

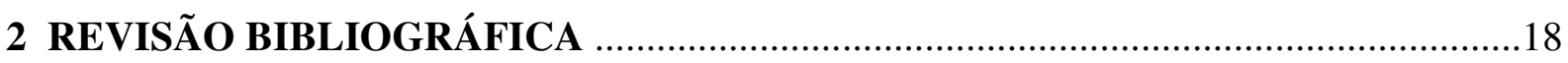

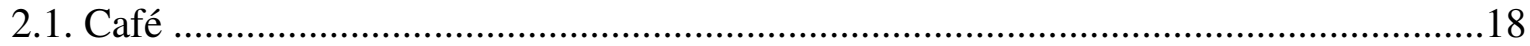

2.1.1. Importância econômica ........................................................................................19

2.1.2. Composição química …………………………………………………………...19

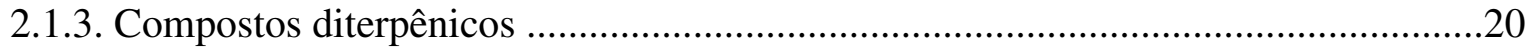

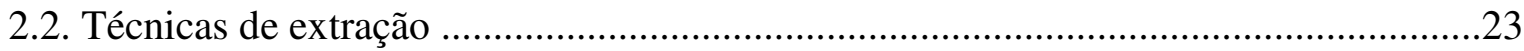

2.2.1. Extração por prensagem mecânica ………………………………………………...23

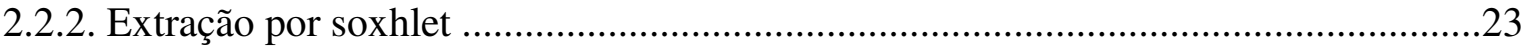

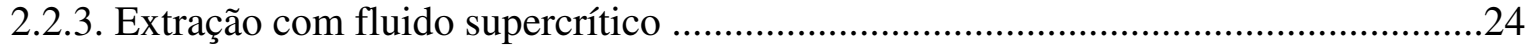

2.2.4. Extração com fluido pressurizado ..........................................................................24

2.3. Quantificação dos diterpenos ..................................................................................25

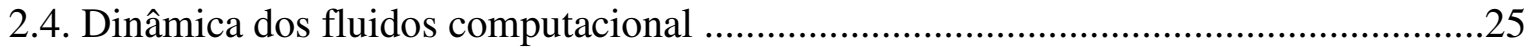

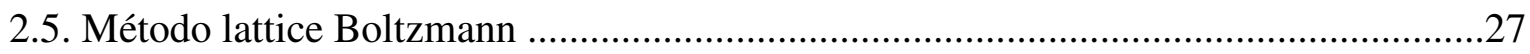

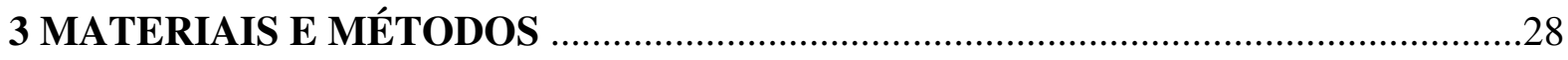

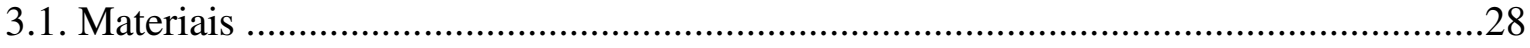

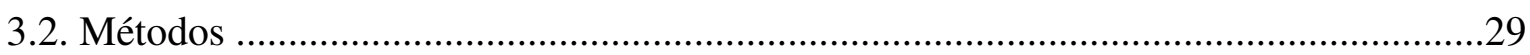

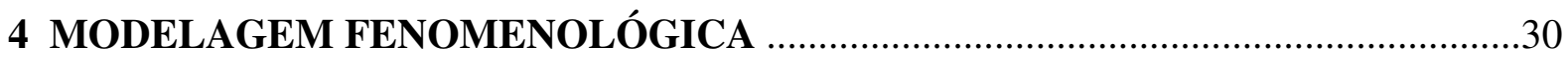

4.1. Introdução ………………………………………………………………………30

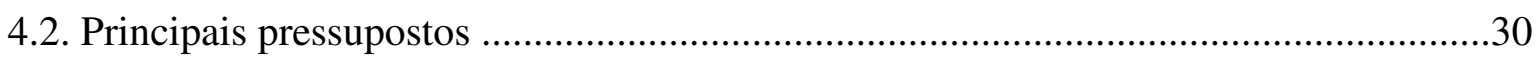

4.3. Descrição matemática ………………………………………………………………...3

4.4. Condições iniciais e de contorno ………………………………………………......33 
5.1. Introdução

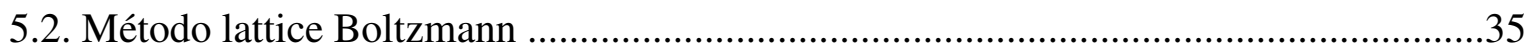

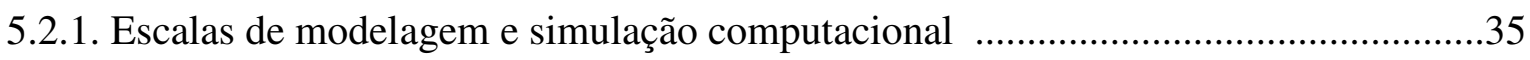

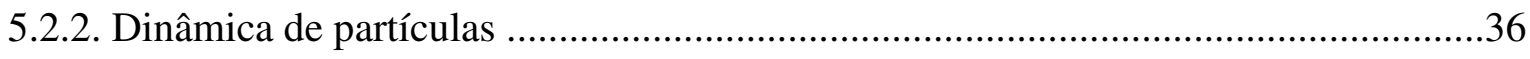

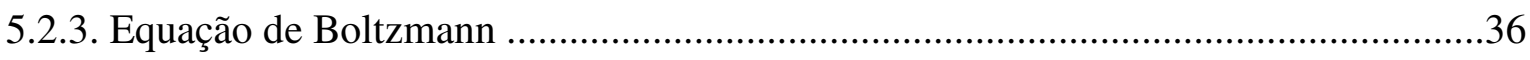

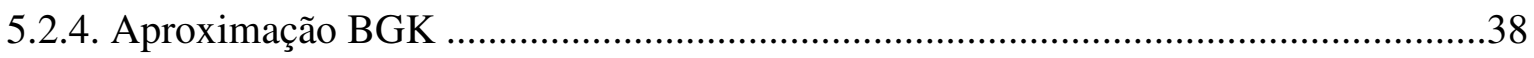

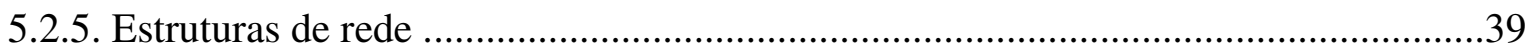

5.2.6. Discretização da equação de Boltzmann ................................................................. 40

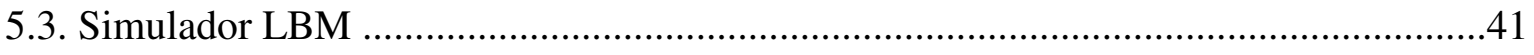

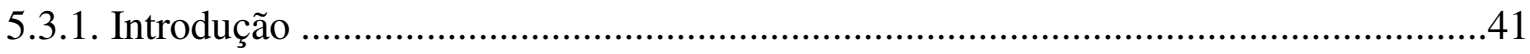

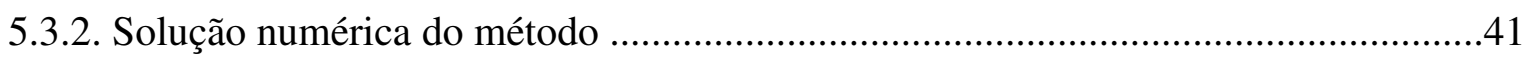

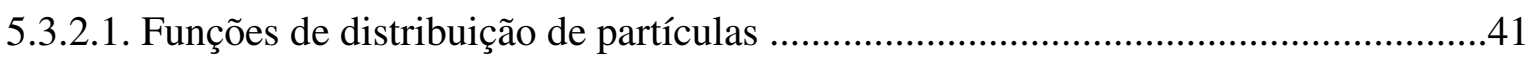

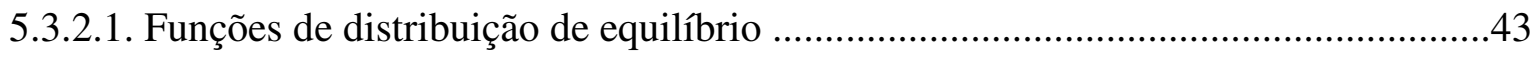

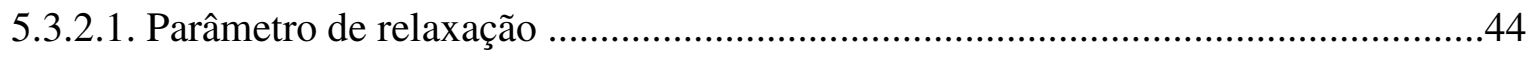

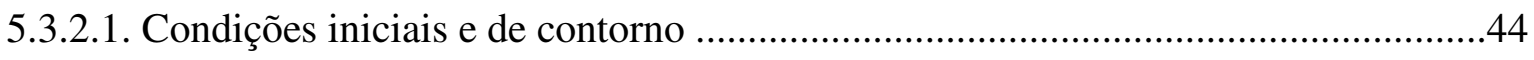

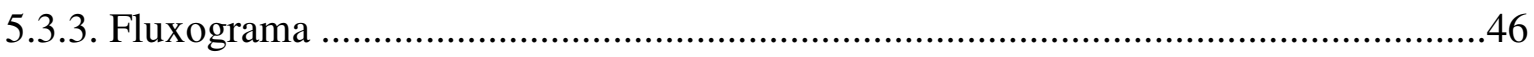

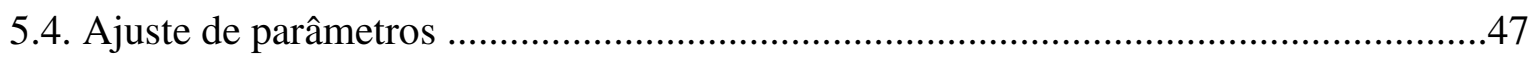

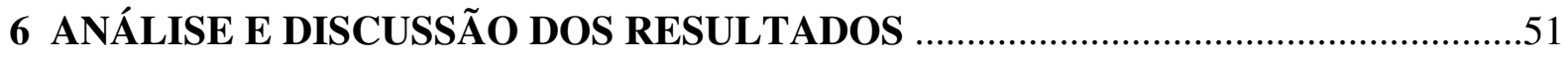

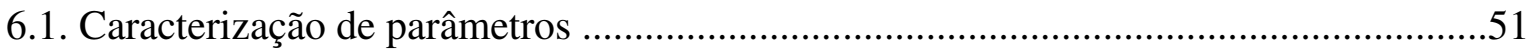

6.1.1. Parâmetros independentes da temperatura .............................................................52

6.1.1.1. Determinação da porosidade do leito ..................................................................52

6.1.1.2. Determinação do coeficiente de formato das partículas .......................................53

6.1.1.3. Determinação do comprimento característico das partículas .................................53

6.1.1.4. Determinação da concentração máxima de extrato na fase sólida ..........................54

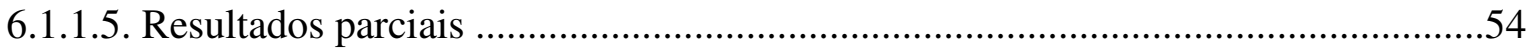

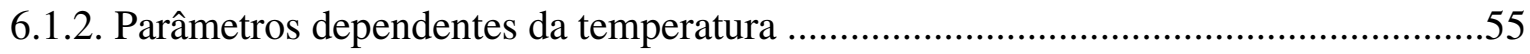

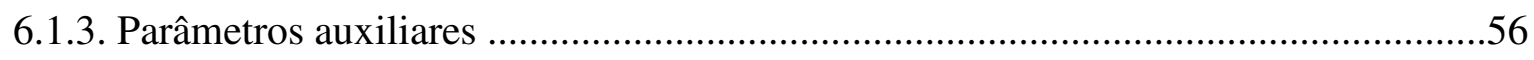

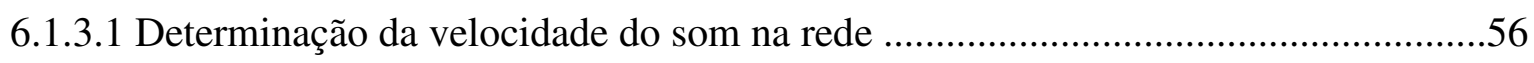

6.1.3.2. Determinação do número de Mach .......................................................................56

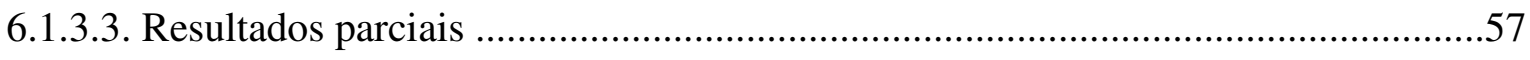

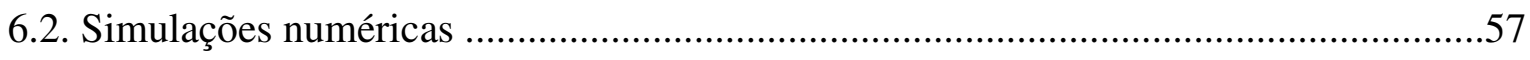


6.2.1. Curvas de concentração de extrato na fase sólida ....................................................57

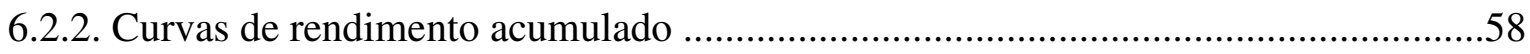

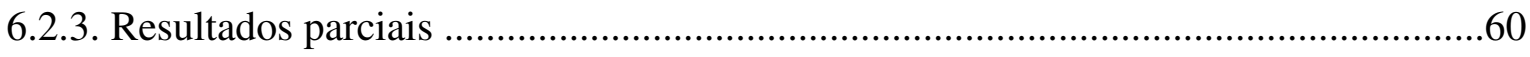

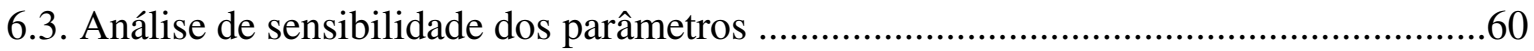

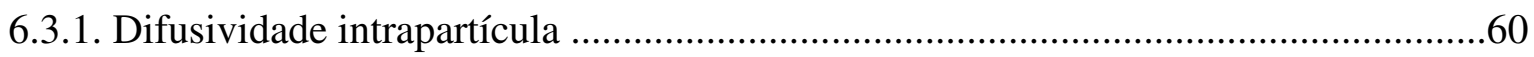

6.3.2. Coeficiente de partição volumétrica ....................................................................61

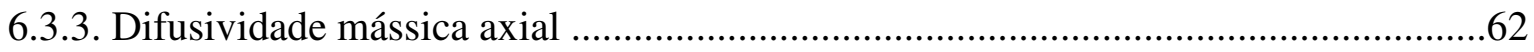

7 CONCLUSÕES

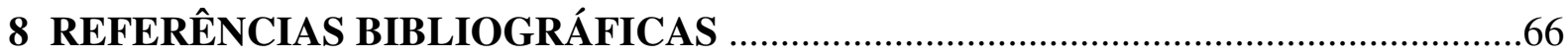




\section{INTRODUÇÃO}

\subsection{Contexto}

O Brasil é um dos líderes mundiais na produção e exportação de produtos agropecuários. No início de 2010, a cada quatro produtos em circulação no mercado internacional, um era brasileiro. É o primeiro produtor e exportador de café, suco de laranja, açúcar e etanol de cana-de-açúcar. Também lidera o ranking das exportações do complexo de soja (BRASIL, 2014).

O café é uma das bebidas mais conhecidas em todo mundo. É um dos mais importantes produtos agrícolas, representando uma das bases do desenvolvimento econômico e social dos países produtores (RINCON, 2011). É um dos produtos básicos mais valiosos no comércio internacional, perdendo apenas para o petróleo. Seu cultivo, processamento, comércio, transporte e marketing criam emprego para milhões de pessoas em todo o mundo. Atualmente, o Brasil é o maior produtor mundial de café, sendo responsável por $33 \%$ do mercado internacional, volume equivalente à soma da produção dos outros seis maiores países produtores. É também o segundo mercado consumidor, atrás somente dos Estados Unidos (ASSOCIAÇÃO BRASILEIRA DA INDÚSTRIA DE CAFÉ, 2014).

O café é uma mistura de vários componentes químicos e pode conter mais de mil produtos químicos diferentes, incluindo compostos fenólicos, carboidratos, lipídeos, compostos nitrogenados, vitaminas, minerais e alcalóides (SPILLER, 1998).

Nos últimos anos, os compostos diterpênicos dos grãos de café verde (cafestol e caveol) têm sido objeto de estudo, especialmente quanto aos aspectos biológicos (TSUKUI et al., 2013). Além de quimioprotetores, também são antioxidantes, antiinflamatórios e possuem efeitos hepatoprotetores (OIGMAN et al., 2012). Ao longo dos anos, pesquisas indicam que o consumo de café com elevado nível de caveol reduz a incidência de câncer do cólon, um dos tipos de câncer mais comum em todo o mundo (GIOVANNUCCI, 1998). Os diterpenos cafestol e caveol são difíceis de serem isolados. Sendo assim, as propriedades biológicas destes compostos têm sido estudadas utilizando uma mistura de ambos, na forma de extrato (CAVIN et al., 2002).

Nas últimas décadas, com o excesso da oferta mundial de café, o produto sofreu uma redução em seu valor comercial, o que incentiva o desenvolvimento de seus 
derivados, com maior valor agregado. O grão de café verde oferece um arsenal de substâncias capazes de acrescentar valor agregado ao mercado do café (TSUKUI et al., 2013).

\subsection{Motivação}

Ao longo dos últimos anos, o método lattice Boltzmann (LBM) tem-se tornado um esquema numérico promissor para simular a complexa dinâmica de fluidos nas mais diversas aplicações (CHEN; DOOLEN, 1998). Desde sua introdução no final dos anos 80 (MCNAMARA; ZANETTI, 1988), o LBM passou por uma série de refinamentos e extensões que o capacitaram a simular com sucesso vários fenômenos, desde a turbulência homogênea de fluidos incompressíveis até escoamentos multifásicos em meios porosos.

Este método se caracteriza pela simplicidade de implementação computacional, quando comparado com outros métodos numéricos para modelagem e simulação computacional (COLLARES, 2012), com grande potencial para simular fluxos turbulentos, fluxos em múltiplas fases e fluxos com condições de contornos irregulares (SUCCI, 1997). É indicado para modelar problemas em que se deseja obter eficiência e facilidade de programação (SCHEPKE; MAILLARD, 2007).

Segundo Komori (2012), as pesquisas com aplicações do método lattice Boltzmann têm crescido significativamente nos últimos anos. A simulação e modelagem de processos agroindústrias utilizando LBM é recente, destaca-se como pioneiro nesta área o orientador desta pesquisa.

\subsection{Objetivos}

\subsubsection{Objetivos gerais}

Com foco na cinética de extração dos componentes diterpênicos do óleo de café verde (cafestol e caveol), esta pesquisa tem como objetivos gerais a correspondente modelagem fenomenológica; a simulação numérica utilizando o método lattice Boltzmann; o ajuste dos parâmetros $\left(D_{i}, D\right.$ e $\left.k_{P}\right)$ através da técnica do gradiente descendente e a análise da influência de tais parâmetros no processo de simulação. 


\subsubsection{Objetivos específicos}

De forma específica, busca-se:

- Descrever o modelo fenomenológico para o processo de extração das espécies químicas (cafestol e caveol), extraídos em sistemas de alta pressão com fluido pressurizado;

- Implementar o código computacional LBM em uma nova linguagem de programação e, a partir deste, simular o processo de extração das espécies químicas;

- Desenvolver e implementar rotina de ajuste dos parâmetros $\left(D_{i}, D\right.$ e $\left.k_{P}\right)$, utilizando o método de gradiente descendente com uso de dados experimentais;

- Desenvolver e implementar interface gráfica para análise de sensibilidade da difusividade intrapartícula, do coeficiente de partição volumétrica e da difusividade mássica axial no processo de simulação via LBM.

\subsection{Organização do texto}

Esta dissertação foi organizada da seguinte forma:

No capítulo 2 constam a revisão bibliográfica do café verde, de seus compostos e suas aplicações na saúde humana; das técnicas de extrações de óleos vegetais, mais especificamente com fluido pressurizado; das técnicas de quantificação dos compostos diterpênicos do café verde; dos principais métodos computacionais empregados na simulação de escoamentos de fluidos; do uso de programas de simulação numérica na área de materiais alimentícios e das simulações com o método lattice Boltzmann.

No capítulo 3 constam as descrições dos materiais e dos métodos, utilizados para simulação computacional via LBM.

No capítulo 4 constam a breve revisão dos principais modelos matemáticos, bem como a descrição do modelo fenomenológico para o processo de extração de espécies químicas a partir de matrizes sólidas, com uso de fluidos pressurizados.

No capítulo 5 constam a simulação computacional via método lattice Boltzmann em uma dimensão, utilizado no simulador para predizer as extrações das 
espécies químicas em sistemas de alta pressão; a fundamentação teórica do método lattice Boltzmann; a solução numérica via LBM e a implementação da técnica do gradiente descendente para ajuste dos parâmetros $\left(D_{i}, D\right.$ e $\left.k_{P}\right)$, com uso de dados experimentais.

No capítulo 6 constam a caracterização dos parâmetros do processo de extração dos compostos diterpênicos do café verde (caveol e cafestol) com fluido pressurizado; as simulações numéricas via método lattice Boltzmann (LBM); a análise e discussão dos resultados.

No capítulo 7 constam as conclusões obtidas neste trabalho de pesquisa, assim como as sugestões para futuros trabalhos.

No capítulo 8 constam as referências bibliográficas utilizadas pelo autor neste trabalho de pesquisa. 


\section{REVISÃO BIBLIOGRÁFICA}

Este capítulo apresenta a revisão bibliográfica do café verde, de seus compostos e suas aplicações na saúde humana; as técnicas de extrações de óleos vegetais, mais especificamente com fluido pressurizado; as técnicas de quantificação dos compostos diterpênicos do café verde; os principais métodos computacionais empregados na simulação de escoamentos de fluidos; o uso de programas de simulação numérica na área de materiais alimentícios e as simulações com o método lattice Boltzmann.

\subsection{Café}

O café é uma das bebidas mais conhecidas e apreciadas em diversos países, pelos aromas e sabores distintos e, nos últimos anos, por seus efeitos benéficos à saúde humana (TRUGO, 2003). O nome café é proveniente da palavra gahwa, que significa vinho. O seu cultivo iniciou-se no século VI, na antiga Abissínia, país localizado na África Central. Entretanto, foi na Arábia que a sua cultura foi desenvolvida em escala comercial. Mais tarde, por volta de 1.600, os turcos levaram o café para Europa e, daí em diante, foi disseminado rapidamente para todo o mundo (NATIONAL COFFEE ASSOCIATION, 2014).

No Brasil, o café foi introduzido no século XVIII, quando algumas mudas foram trazidas da Guiana Francesa e disseminadas em toda a costa, chegando ao Rio de Janeiro, São Paulo e ao Paraná, tornando o País o maior produtor e exportador mundial de café (AGRIANUAL, 2002).

Em relação à classificação botânica, o café pertence ao grupo das plantas Fanerógramas, da classe Angiosperma, da subclasse Dicotiledônia, da ordem Rubiales, da família Rubiaceae, da tribo Coffeae, da subtribo Coffeinae e do gênero Coffea (MATIELLO, 2005). O grão é obtido do cafeeiro, uma árvore de folhas verdes, tipo arbusto de origem tropical.

A espécie Coffea arábica fornece uma bebida de qualidade superior, aroma agradável, com variações de acidez e melhor sabor. A espécie Coffea canéfora, conhecida também como conilon, produz uma bebida de qualidade inferior, mais amargo (RINCON, 2011). 

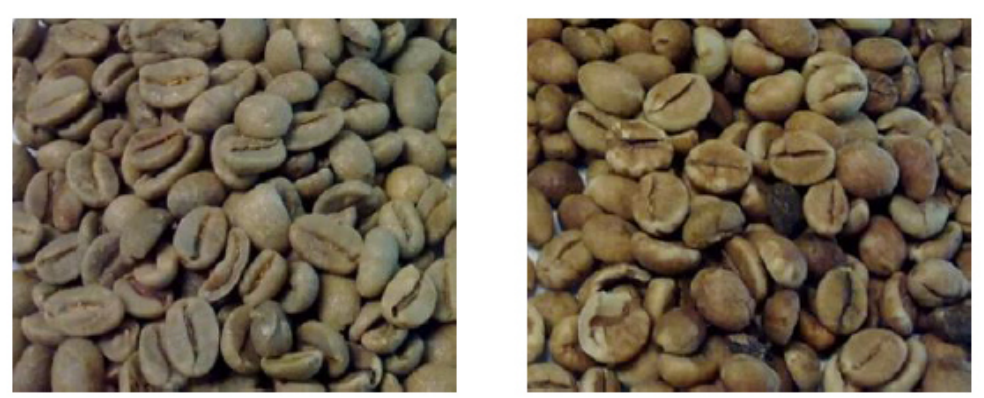

Figura 1. Grãos de café verde arábica (esquerda) e robusta (direita) Fonte: TSUKUI et al., 2013.

\subsubsection{Importância econômica}

O café é um dos produtos básicos mais negociados nos mercados internacionais, tornando-se uma cultura de grande importância econômica (RINCON, 2011), pois é muito consumido desde que se percebeu sua propriedade de aumentar a concentração (WAGEMAKER, 2009).

O Brasil é o maior produtor e exportador de café. Em 2013 foram produzidas 49 milhões de sacas de 60 quilos de café, representando 33\% da produção mundial e foram exportadas 32 milhões de sacas, representando $28 \%$ das exportações mundiais de café (AGRIANUAL, 2014). A estimativa para exportação de café em 2014 é de 33 milhões de sacas de 60 quilos (EMPRESA BRASILEIRA DE PESQUISA AGOPECUÁRIA, 2014). É também o segundo mercado consumidor, atrás somente dos Estados Unidos (ABIC, 2014).

Atualmente, o país possui um parque cafeeiro de 2.311 milhões de hectares, com cerca de 290 mil produtores, em aproximadamente 1.900 municípios, gerando emprego para 8,4 milhões de pessoas, em toda a sua cadeia produtiva (BRASIL, 2014). As principais regiões cafeeiras estão situadas nos estados de Minas Gerais, Espírito Santo, São Paulo e Paraná (ABIC, 2014).

\subsubsection{Composição química}

O café verde é uma mistura complexa de componentes químicos e pode conter mais de mil produtos químicos diferentes (SPILLER, 1998). Segundo Lima et al. (2010), fatores como genética, sistema de cultivo, época de colheita, processo de manipulação e conservação do grão, armazenamento e torrefação podem influenciar na composição química do café verde. Além da água, tem em sua composição grande variedade de 
minerais, carboidratos, ácidos, aminoácidos, proteínas, lipídeos, cafeína, vitaminas, fenóis e enzima, entre outros (DEDECCA, 1957; PIMENTA et al., 2008).

O grão de café contém de 7 a $17 \%$ de lipídeos, tendo como principais componentes os triglicerídeos $(75,2 \%)$, ésteres de álcoois diterpênicos e ácidos graxos $(18,5 \%)$, álcoois diterpênicos $(0,4 \%)$, ésteres de esteróis $(3,2 \%)$, esteróis $(2,2 \%)$, tocoferóis $(0,05 \%)$, fosfatídeos $(0,1$ a $0,5 \%)$ e derivados de triptamina $(0,8 \%)$ (FOLSTAR, 1985), que podem ser utilizado como emolientes, emulsificantes, modificadores de viscosidade e agentes de propagação, dentre outras aplicações (OLIVEIRA, 2013).

O óleo de café é constituído principalmente de ceras, triglicerídeos e matéria insaponificável (TANGO, 1971). Os grãos contêm de 0,2 a 0,3\% de cera, localizada na camada externa do grão (WAGEMAKER, 2009). A cera do café possui efeito antioxidante quando utilizada em alimentos como óleos e gorduras (LEHMANN et al., 1972).

De acordo com Wagemaker (2009), o óleo de café é rico também em matéria insaponificável, como esteróis, tocoferóis, fosfatídeos e ceramidas, entre outros componentes, o que confere certa dificuldade para seu refinamento. Entretanto, possui propriedades cosméticas de retenção da umidade, penetração e aderência na pele (TURATTI; LUCCAS, 2001). Os principais constituintes do material insaponificável são dois álcoois diterpênicos, o cafestol $\left(\mathrm{C}_{20} \mathrm{H}_{28} \mathrm{O}_{3}\right)$ e o caveol $\left(\mathrm{C}_{20} \mathrm{H}_{26} \mathrm{O}_{3}\right)$, que ocorrem na forma livre ou como monoésteres de ácidos graxos (WAGEMAKER, 2009).

\subsubsection{Compostos diterpênicos}

O óleo de café contém diterpenos em proporção de até $20 \%$ dos lipídios totais (ESQUIVEL; JIMENÉZ, 2011; KURZROCK; SPEER, 2001).

Os diterpenos caveol $\left(\mathrm{C}_{20} \mathrm{H}_{26} \mathrm{O}_{3}\right)$ e cafestol $\left(\mathrm{C}_{20} \mathrm{H}_{28} \mathrm{O}_{3}\right)$ são classificados como álcoois de diterpenos pentacíclicos baseados na fusão de unidade de isopreno, com 5 átomos de carbono para formar o esqueleto caurano, grupo de diterpenos ciclizados em 4 anéis, de 20 átomos carbonos como típicos constituintes lipídicos, que não têm sido detectados em nenhum outro alimento (RINCON, 2011). A figura 2 ilustra a estrutura molecular destes compostos. 


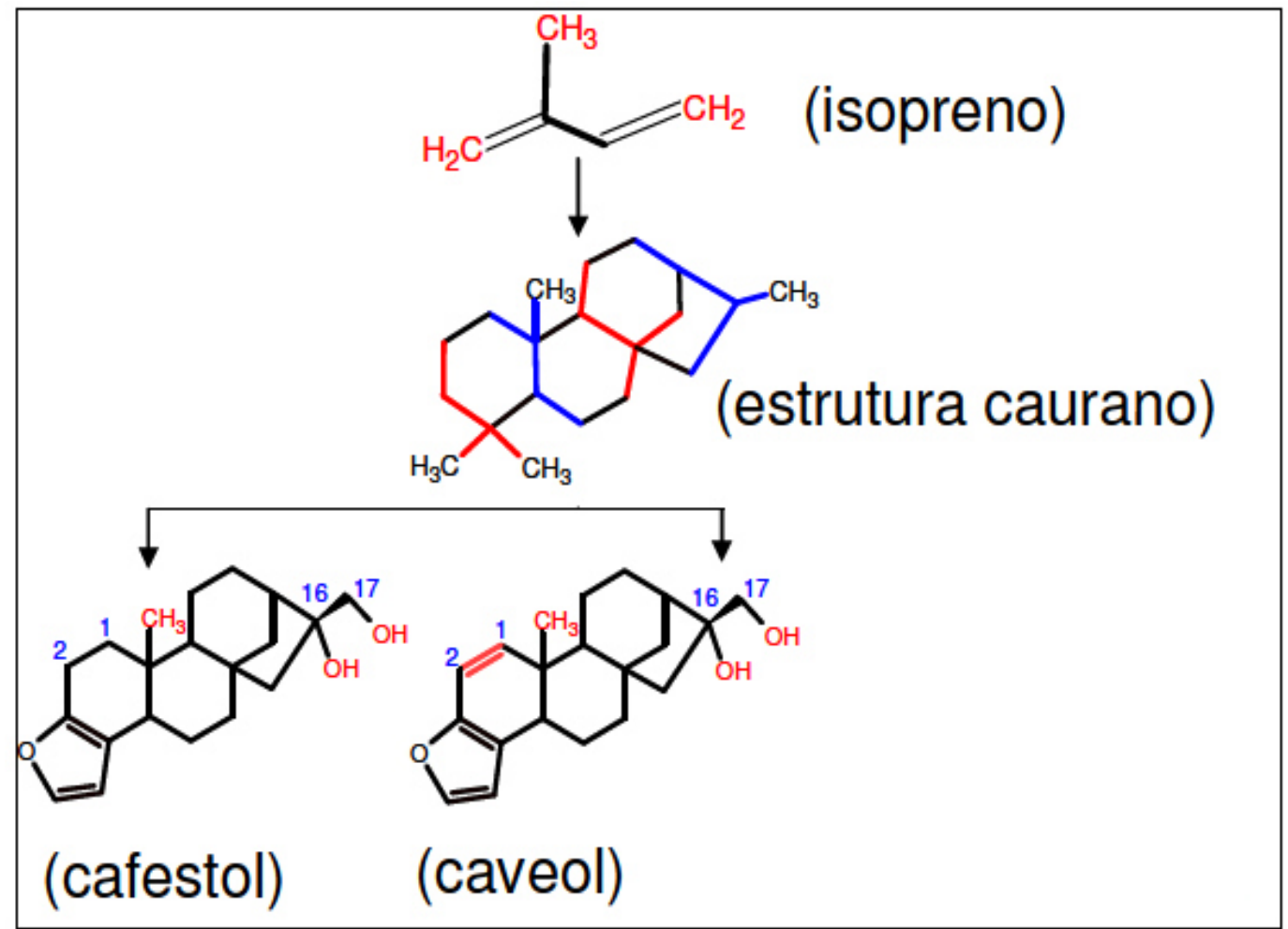

Figura 2. Estrutura dos principais diterpenos do café verde (caveol e cafestol) Fonte: Adaptação de RINCON, 2011.

A diferença estrutural entre a molécula cafestol e caveol é pequena. $\mathrm{O}$ caveol apresenta uma dupla ligação entre os carbonos 1 e 2 , enquanto o outro apresenta uma ligação simples. Esta diferença resulta em um espectro com pico de absorção em diferentes comprimentos de ondas, sendo 220nm para o cafestol e 290nm para o caveol (SPEER; KÖLLING-SPEER, 2006), conforme ilustra a figura 3.

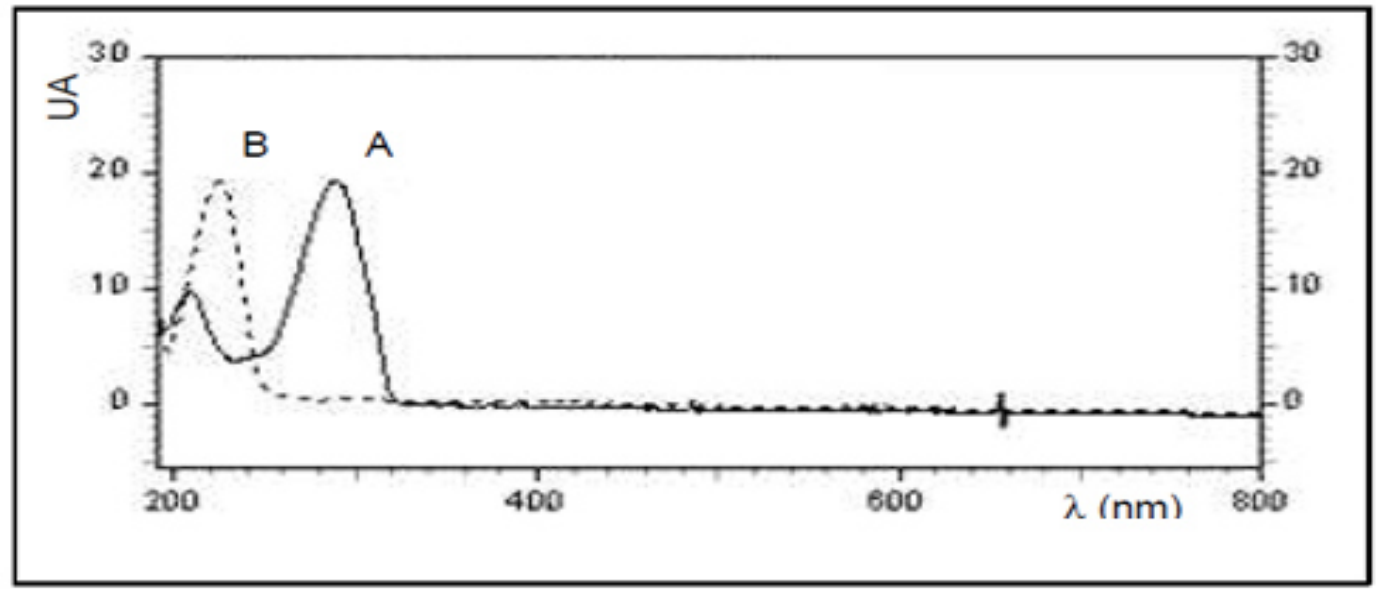

Figura 3. Espectro de absorção (190nm a 800nm) de caveol (A) e cafestol (B), obtidos com padrão comercial Fonte: adaptado de DIAS, 2009. 
O caveol é uma substância sensível ao oxigênio, à luz e ao calor, e é responsável pela cor amarela do óleo (HARWORTH et al., 1955). Nos últimos anos, os diterpenos de café têm recebido destaque pelos efeitos benéficos à saúde humana, por sua ação antioxidante (CHU et al., 2011; LEE et al.,2007); anti-inflamatória, (CHU et al., 2011; KIM et al., 2006); anticarcinogênica (HATZOLD, 2012; BUTT; SULTAN, 2011; MURIEL; ARAUZ, 2010; CAVIN et al., 2002); por seus efeitos hepatoprotetores (LEE et al., 2007; MURIEL; ARAUZ, 2010) e menor risco de diabetes mellitus tipo 2 (CHU et al., 2011).

Pesquisas indicam que estas substâncias possuem propriedades de proteção contra raios solares, podendo assim ser utilizadas na formulação de filtros solares (CAVIN et al., 2002). No decorrer dos anos, companhias multinacionais obtiveram patentes para aplicação destes compostos, devido às suas funções de quimioproteção (DIAS, 2009). A primeira referência sobre o uso do óleo de café como protetor solar é a patente US 4.793.990, de Grollier e Plessis (1988).

Outra propriedade relevante dos diterpenos é o seu potencial anticarcinogênico, que para Huber et al. (2002), futuramente tais substâncias poderão ser utilizadas na indústria alimentícia como aditivo.

Ao longo dos anos, pesquisas apontam que o consumo de café com elevado nível de caveol reduz a incidência de câncer do cólon, um dos tipos mais comum em todo o mundo (GIOVANNUCCI, 1998). Ressalta-se que o teor de diterpenos (cafestol e caveol) presente na bebida depende do preparo. A bebida preparada no estilo escandinavo e turco contém os maiores teores de caveol e cafestol, enquanto que o café expresso contém quantidades intermediárias e, o café filtrado, valores desprezíveis. (CAMPANHA, 2008; RICKETTS et al., 2007; URGERT et al.,1995).

Diante de tal panorama, aumenta cada vez mais o interesse em desenvolver cultivares de café com maior teor de diterpenos. O Instituto Agronômico de Campinas (IAC) desenvolve desde 1934 programas de melhoramento genético, com a finalidade de aumentar a variabilidade genética e permitir a seleção de melhores cultivares (WAGEMAKER, 2009).

Neste contexto, cresce o estudo de novas técnicas e metodologias de extração do óleo de café enriquecido com esses compósitos (TSUKUI et al., 2013), bem como o estudo de novas técnicas de quantificação dessas substâncias. 


\subsection{Técnicas de extração}

Nos últimos anos, quase $40 \%$ das drogas modernas foram desenvolvidas a partir de produtos naturais, despertando assim o interesse das empresas farmacêuticas em produtos naturais como fonte de novos medicamentos (RINCON, 2011). Os óleos vegetais vêm sendo empregados em aplicações industriais, nos setores de alimentos, fármacos e cosméticos (GASSENMEIER et al., 1998). Frente a este cenário, tem-se investido em diversas técnicas de extrações de óleos a partir de matrizes vegetais. Dentre as técnicas, destaca-se a extração por prensagem mecânica; por soxhlet; com fluido supercrítico e com fluido pressurizado.

\subsubsection{Extração por prensagem mecânica}

A extração por prensagem mecânica é a técnica mais antiga e o principal método de extração comercial de óleo a partir de matrizes vegetais. Tem sido utilizada na obtenção de óleo de café e seus compostos (CHARTIER, et al., 2013; TSUKUI et al., 2013). Por não utilizar solvente preserva as propriedades naturais do óleo, entretanto, apresenta um rendimento menor que o processo de extração com solvente químico (TSUKUI et al., 2013).

A técnica consiste no emprego de prensas hidráulicas ou mecânicas, com cestos formados de barras de aço retangulares e distanciados por meio de lâminas, com regulagem de espessura, de forma a permitir a saída do óleo e a filtragem das partículas do resíduo da prensagem (PIGHINELLI, 2010).

\subsubsection{Extração por soxhlet}

O método de extração sólido-líquido em extrator Soxhlet é uma das técnicas mais relatadas para extração do óleo de café (DE MELO et al., 2014; SCHARNHOP; WINTERHALTER, 2009; NAIDU et al., 2008; OLIVEIRA et al., 2008).

No extrator Soxhlet ocorre a passagem do solvente pela amostra, por refluxo aquecido, seguida da remoção por evaporação ou destilação do solvente (SOXHLET, 1879). Esta técnica apresenta maior rendimento de óleo em relação à extração por prensagem mecânica devido ao contato direto do solvente com o grão durante todo o período de extração (TSUKUI et al., 2013; BRUM et al., 2009). 


\subsubsection{Extração com fluido supercrítico}

A extração com fluido supercrítico (SFE) é uma técnica alternativa e limpa, pois geralmente utiliza como solvente o dióxido de carbono $\left(\mathrm{CO}_{2}\right)$, o que permite obter extratos com elevado grau de purificação, livres de solventes orgânicos e com baixas perdas de componentes termossensíveis (SUTTER et al., 1994).

Em escala industrial, a técnica teve seu início na Alemanha, com o processo de remoção da cafeína do café (MAUL, 1999). Na área acadêmica tem sido empregada para obtenção do óleo de café (BARBOSA et al., 2014; DE MELO et al., 2014; AZEVEDO et al., 2008); de gengibre (MESOMO et al., 2012); de canola (PEDERSSETTI et al., 2011); de amêndoas (MARRONE et al., 1998); de palma (CORRÊA et al., 2001) e de oleoresina de cavalinha (MICHIELIN et al., 2001).

A indústria de alimentos tem utilizado o $\mathrm{CO}_{2}$ como solvente na extração SFE, pois é uma substância com baixa toxicidade, não carcinogênico, não inflamável, não prejudicial à saúde humana quando inalado a baixas concentrações e de fácil remoção do material extraído (MAUL, 1999; DANH et al., 2009).

\subsubsection{Extração com fluido pressurizado}

A extração com fluido pressurizado (PFE) é uma técnica recente, que utiliza menos solvente e é livre de oxigênio e luz ambiente (DODDS et al., 2004). Tem sido utilizada na obtenção de extratos de café verde enriquecidos com componentes bioativos (OLIVEIRA, 2013; BELANDRIA et al., 2014); na extração de ácidos triterpênicos de Glycirrhiza glaba, ricos em compostos ativos (CLAUDE et al., 2008); na extração de compostos fenólicos do farelo de sorgo (BARROS et al., 2013); na separação de compostos lipídicos das sementes de Amaranthus (KRAUJALIS et al., 2013); na extração de compostos fenólicos da linhaça (KANMAZ, 2014) e de óleos essências de Foeniculum vulgare Miller (SOLANA et al., 2014).

A extração PFE pode ser feita pelo método estático ou dinâmico. No método estático, a amostra é acondicionada em um extrator com solvente apropriado, com condição de temperatura, pressão e tempo estático pré-definido e, posteriormente, o solvente é purgado em um coletor. Enquanto que, no método dinâmico o solvente é continuamente bombeado através da amostra. Tais solventes podem ser usados em condições próximas de sua região supercrítica, permitindo assim maiores rendimentos na 
extração, tornando a técnica mais eficiente e rápida na obtenção de extratos a partir de fontes vegetais (OLIVEIRA, 2013).

Liderado pelo Dr. Stephane Bostyn, o laboratório de processos (Laboratoire de Procédés) da Université d'Orléans, na França tem utilizado esta técnica para obtenção de extratos enriquecidos com compostos diterpênicos do café verde (cafestol e caveol), com cinéticas de excelentes rendimentos. Tais resultados experimentais foram disponibilizados ao autor deste trabalho e serão utilizados para fins de validação do modelo computacional.

\subsection{Quantificação dos diterpenos}

Assim como as técnicas de extração de óleos vegetais, várias técnicas de quantificação dos compostos diterpênicos de café verde têm sido estudadas nos últimos anos. Como são os casos da análise por espectroscopia de ressonância magnética nuclear, que utiliza uma quantidade mínima da amostra do óleo de café, solvente orgânico e sem provocar degradação do material (D’AMELIO et al., 2013), e do uso de Espectroscopia Raman (WERMELINGER et al., 2011, KEIDEL et al., 2010, RIBEIRO et al., 2010).

$\mathrm{Na}$ quantificação desses compostos têm sido empregadas em sua maioria as técnicas de cromatografias. Como é o caso da técnica de cromatografia gasosa (GUERRERO et al., 2005; CASTILLO et al., 1999; ROOS et al., 1997). A técnica de cromatografia líquida é considerada de alta eficiência por ser uma técnica rápida e prática, que permite a análise dos componentes sem derivatização da amostra e evitando a degradação térmica (BELANDRIA et al., 2014; DIAS et al., 2010; ARAÚJO; SANDI, 2006).

\subsection{Dinâmica dos fluidos computacional}

O estudo do movimento dos fluidos é uma atividade que vem sendo desenvolvida ao longo dos séculos (FORTUNA, 2012). O conhecimento dos fenômenos físicos que ocorrem em meios fluidos tem permitido ao homem um avanço crescente no desenvolvimento técnico e científico, propiciando-lhe melhores condições de sobrevivência (SCHIOZER, 1996).

Segundo Fortuna (2012), o primeiro cientista a deduzir as equações do movimento foi Leonard Euler. Porém, as descrições matemáticas do comportamento dos fluidos só ganharam força no século XIX, na forma das equações de Navier-Stokes, a partir 
dos trabalhos pioneiros dos franceses Claude Navier (1822) e Simeon Poisson (1831), e do inglês George Stokes (1845).

A dinâmica dos fluidos computacional (CFD) é área da computação científica que estuda métodos computacionais para simulação de fenômenos de transporte envolvendo fluidos em movimento (FORTUNA, 2012), objeto de estudo deste trabalho de pesquisa. Ressalta-se que o uso de métodos computacionais de maneira alguma implica que a mecânica dos fluidos experimental e as análises teóricas estejam sendo postas de lado (FORTUNA, 2012).

Aponta Maliska (1995), que a partir dos anos 60, com notável avanço dos computadores de alta velocidade e sua disponibilidade nas universidades e centros de pesquisa, o uso de técnicas numéricas para a solução de complexos problemas de engenharia e de física tornou-se uma realidade. Com isso, foi possível implementar programas de simulação capazes de representar diferentes tipos de escoamentos. $\mathrm{O}$ autor supracitado reafirma que a utilização de metodologia experimental é importante, pois lida com a configuração real do problema. No entanto, o fenômeno em estudo nem sempre é passível de reprodução em laboratório, pois pode ser de altíssimo custo e, muitas vezes, não pode ser realizado por questões de segurança.

Como ferramenta para pesquisa, desenvolvimento e inovação (PD\&I) de processos, a simulação tem como objetivo central reduzir o número de experimentos e explorar fenômenos que não poderiam ser estudados em laboratórios de forma prática. Utilizando CFD, pode-se avaliar numericamente os diversos parâmetros do problema, os quais podem ser alterados até que o resultado da simulação atenda às exigências do projeto ou do processo em estudo (ZACHI, 2006).

Norton e Sun (2007) apontam um crescimento no uso de programas de simulação numérica na área de alimentos, como a simulação da estocagem de amendoim (CASADA; YOUNG, 1994), o assar de biscoitos (DE VRIES; VELTHUIS; KOSTER, 1995) e a secagem de soja (TRINDADE, 2013).

Dentre os métodos numéricos mais difundidos para simular escoamento de fluidos, destacam-se o método de diferenças finitas (MDF), o método de elementos finitos (MEF) e o método de volumes finitos (MVF) (WANG; SUN, 2003), sendo o último mais utilizado para simular processamentos térmicos de alimentos (VAN DER SMAN, 2003). 


\subsection{Método lattice Boltzmann}

Segundo Collares (2012), o método lattice Boltzmann (LBM) tem sua origem histórica no método lattice gas celular automata (LGCA), mas com uma abordagem mesoscópica, passando a modelar distribuições de micropartículas ao invés de cada micropartícula. De acordo com Chopard et al. (2002), o LBM é também uma forma simplificada da equação cinética de Boltzmann, na qual os detalhes de movimentação molecular são descartados, com exceção daqueles necessários à recuperação do comportamento macroscópico correto.

As pesquisas com o método lattice Boltzmann têm crescido significativamente nos últimos anos (KOMORI, 2012). Como exemplos, citam-se o uso do LBM na análise de transferência de calor por radiação (MISHRA, et al., 2014), e na simulação de fluxos térmicos incompressíveis (ARUMUGA; ANOOP, 2014), entre outros.

No Brasil, pode-se destacar o Instituto de Informática (INF) da Universidade Federal do Rio Grande do Sul (UFRGS), com trabalhos na área de computação paralela (SCHEPKE; MAILLARD, 2007); o Laboratório Nacional de Computação Científica (LNCC), com trabalho na área de modelagem de escoamentos de fluidos incompressíveis (GOLBERT, 2009), e animação de fluidos (JUDICE, 2009). Na área de processos agroindústrias, cita-se (OKIYAMA; RABI, 2013).

Devido ao seu grande potencial na simulação de fluxos turbulentos em múltiplas fases e com condições de contorno irregulares, o LBM é frequentemente utilizado como um modelo alternativo para simulação computacional da dinâmica de fluidos (SUCCI, 1997).

De acordo com Komori (2012), as simulações com LBM vão além da dinâmica dos fluidos, incluindo outras áreas como a acústica (VIGGEN, 2009), o eletromagnetismo (MENDONZA; MUNOZ, 2010) e a mecânica quântica (SUCCI, 2001). 


\section{MATERIAIS E MÉTODOS}

Neste capítulo constam os dados dos materiais de pesquisa (cafestol e caveol), e os métodos empregados na simulação computacional da extração das espécies químicas em sistemas de alta pressão.

\subsection{Materiais}

Os materiais estudados neste trabalho de pesquisa foram os compostos diterpênicos do café verde (cafestol e caveol). As cinéticas destes compostos foram disponibilizadas pelo laboratório de processos (Laboratoire de Procédés) da Université d'Orléans, na França, cujas pesquisas são lideradas pelo Dr. Stephane Bostyn.

Estes compostos foram obtidos a partir de amostras de grãos de café verde arábica da região de São Paulo, extraídos em sistema de alta pressão com fluido pressurizado (PFE) e com a utilização do solvente metanol. A quantificação destas substâncias foi através de cromatografia líquida de alta eficiência (HPLC).

Nas tabelas 1 e 2 constam os dados (massa extraída em gramas) das cinéticas de extração dos compostos diterpênicos (cafestol e caveol), respectivamente. A caracterização dos parâmetros do processo de extração encontra-se no capítulo 6 deste trabalho de pesquisa.

Tabela 1. Cinéticas da extração de cafestol via PFE.

\begin{tabular}{cccc}
\hline Tempo (min) & $\mathbf{6 0}^{\mathbf{9}} \mathbf{C}$ & $\mathbf{8 0}^{\mathbf{}} \mathbf{C}$ & $\mathbf{1 0 0}^{\mathbf{C}} \mathbf{C}$ \\
\hline 30 & $45,54 \mathrm{~g}$ & $41,70 \mathrm{~g}$ & $54,18 \mathrm{~g}$ \\
50 & $4,16 \mathrm{~g}$ & $9,83 \mathrm{~g}$ & $13,22 \mathrm{~g}$ \\
72 & $2,83 \mathrm{~g}$ & $6,62 \mathrm{~g}$ & $8,41 \mathrm{~g}$ \\
102 & $4,38 \mathrm{~g}$ & $7,41 \mathrm{~g}$ & $6,97 \mathrm{~g}$ \\
133 & $2,06 \mathrm{~g}$ & $4,33 \mathrm{~g}$ & $4,58 \mathrm{~g}$ \\
165 & $2,17 \mathrm{~g}$ & $3,52 \mathrm{~g}$ & $4,90 \mathrm{~g}$ \\
\hline
\end{tabular}

Fonte: Belandria et al., 2014. 
Tabela 2. Cinéticas da extração de caveol via PFE.

\begin{tabular}{cccc}
\hline Tempo (min) & $\mathbf{6 0}^{\circ} \mathbf{C}$ & $\mathbf{8 0}^{\circ} \mathbf{C}$ & $\mathbf{1 0 0}^{\mathbf{C}} \mathbf{C}$ \\
\hline 30 & $70,75 \mathrm{~g}$ & $79,80 \mathrm{~g}$ & $81,24 \mathrm{~g}$ \\
50 & $7,29 \mathrm{~g}$ & $15,79 \mathrm{~g}$ & $20,33 \mathrm{~g}$ \\
72 & $5,95 \mathrm{~g}$ & $9,72 \mathrm{~g}$ & $9,27 \mathrm{~g}$ \\
102 & $6,97 \mathrm{~g}$ & $12,19 \mathrm{~g}$ & $12,23 \mathrm{~g}$ \\
133 & $3,39 \mathrm{~g}$ & $7,13 \mathrm{~g}$ & $7,58 \mathrm{~g}$ \\
165 & $3,52 \mathrm{~g}$ & $5,23 \mathrm{~g}$ & $7,30 \mathrm{~g}$
\end{tabular}

Fonte: Belandria et al., 2014.

\subsection{Métodos}

Para modelagem fenomenológica do processo de extração dos compostos diterpênicos, em sistema de alta pressão com fluido pressurizado foi proposto um modelo baseado em balanços diferenciais de massa, aplicados às fases sólida e fluida. Na fase sólida ocorre o fenômeno de difusão intrapartícula e na fase fluida ocorrem tanto a difusão como convecção, ambas na direção axial (ROSA et al., 2014; RABI, 2011). A descrição detalhada de tal modelo encontra-se no capítulo 4 deste trabalho de pesquisa.

$\mathrm{Na}$ simulação computacional foi empregado o método numérico lattice Boltzmann (LBM), que consiste na implementação de uma dinâmica de partículas composta por colisões e propagações. Para o ajuste (otimização) dos parâmetros $\left(D_{i}, D\right.$ e $k_{p}$ ) foi implementada a técnica do gradiente descendente.

Nesta pesquisa foi utilizada a linguagem de programação Python, tanto para a implementação do método LBM quanto à técnica de otimização. A descrição do LBM, bem como da técnica de otimização dos parâmetros, e seus respectivos fluxogramas computacionais encontram-se no capítulo 5 deste trabalho de pesquisa. 


\section{MODELAGEM FENOMENOLÓGICA}

Este capítulo consta de uma breve revisão dos principais modelos matemáticos, bem como a descrição do modelo fenomenológico para o processo de extração de espécies químicas a partir de matrizes sólidas, com uso de fluidos pressurizados.

\subsection{Introdução}

A modelagem de um problema físico requer muita habilidade na criação do modelo matemático, pois os resultados obtidos devem representar o fenômeno físico em questão (MALISKA, 1995). Segundo Steffani (2003), um dos primeiros modelos matemáticos para extração de óleo vegetal foi proposto por Bulley et al., (1984). Este modelo foi baseado em balanços diferenciais de massa para o processo de extração do óleo de canola.

De modo geral, os modelos matemáticos para extração de óleo podem ser classificados em três categorias: os que são baseados em modelos empíricos, outros em analogias de transferência de calor e, por fim, aqueles que são baseados na integração de um balanço diferencial de massa (VARGAS et al., 2006). Entre os modelos empíricos destacam-se (SILVA et al., 2008; NGUYEN et al., 1991; NAIK et al., 1989) os baseados na transferência de calor (BARTLE et al., 1990), tendo como parâmetro ajustável a difusividade intrapartícula. Quantos aos modelos que utilizam balanço diferencial de massa têm-se (OKIYAMA; RABI, 2013; MELRELES et al., 2009; LUCAS et al., 2007; VARGAS et al., 2006; REIS-VASCO et al., 2000; REVERCHON, 1996; GOTO et al., 1993).

\subsection{Principais pressupostos}

O modelo proposto neste trabalho de pesquisa é baseado em balanços diferenciais de massa, aplicados às fases sólida e fluida. Na fase sólida ocorre o fenômeno de difusão intrapartícula e na fase fluida ocorrem tanto a difusão como convecção, ambas na direção axial (ROSA et al., 2014; RABI, 2011).

O processo de extração inicia-se quando as condições de pressão e temperatura (dentro do extrator) são atingidas, ou seja, trata-se de um sistema isotérmico e isobárico. 
Em seguida, um fluxo constante de solvente atravessa a célula carregando consigo a espécie química.

Cada extrato de interesse (cafestol e caveol) é tratado como sendo um único componente (ROSA et al., 2014; RABI, 2011; VARGAS et al., 2006; REVERCHON, 1996). As características das partículas (grãos de café verde) são consideradas (VARGAS et al., 2006; REVERCHON, 1996). Os parâmetros difusividade intrapartícula $\left(D_{i}\right)$, difusividade mássica axial $(D)$ e coeficiente de partição volumétrica $\left(k_{\mathrm{P}}\right)$ são ajustados com uso de dados experimentais (ROSA et al., 2014).

\subsection{Descrição matemática}

Neste item consta a descrição matemática do modelo fenomenológico para representar as extrações das espécies químicas, em sistemas de alta pressão com fluido pressurizado. Este modelo é de autoria do orientador desta pesquisa e foi disponibilizado para realização deste trabalho.

$\mathrm{Na}$ maioria dos equipamentos de extração com uso de fluido supercrítico ou pressurizado, as amostras são acondicionadas em extratores cilíndricos. Sendo assim, na modelagem fenomenológica da extração com fluido pressurizado, adotou-se o sistema como sendo composto por um extrator cilíndrico na vertical. O leito é fixo com comprimento $L$ e raio $R$, a entrada é em $\mathrm{z}=0$ (parte superior do leito), enquanto a saída é em $z=L$ (parte inferior do leito), conforme esquema da figura 4(a) (RABI, 2011).

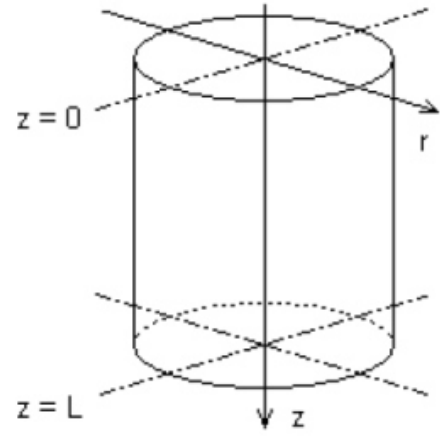

(a)

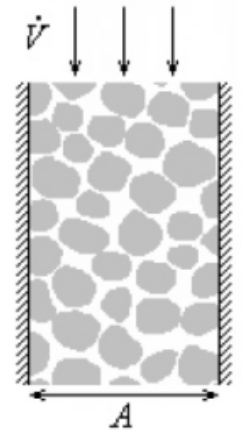

(b)

Figura 4. (a) Leito fixo em sistema de coordenadas cilíndricas; (b) velocidade intersticial Fonte: Adaptado de RABI, 2011. 
Tendo em mente que neste processo a vazão volumétrica $\dot{V}$ do solvente é constante ao longo do leito (REVERCHON, 1996), bem como a porosidade ( $\varepsilon$ ) (RABI, 2011) a velocidade intersticial do escoamento pode ser analisada através da Eq. (1):

$$
v=\frac{\dot{V}}{\varepsilon \cdot A}
$$

onde $A=\pi R^{2}$ é a área da seção transversal do leito.

Como se trata de um modelo dinâmico de primeira ( $\left.1^{\mathrm{a}}\right)$ ordem espacial, assume-se que as concentrações de extrato possam variar com o tempo $t$ e com a coordenada axial $z$ do leito. De forma que, $\psi=\psi(z, t)$, refere-se às concentrações na fase sólida e, $\phi=\phi(z, t)$, refere-se às concentrações na fase fluida. Através de um balanço diferencial de massa tem-se a equação governante para as concentrações de extrato na fase sólida $\psi($ OKIYAMA; RABI, 2013):

$$
(1-\varepsilon) d V \frac{\partial \psi}{\partial t}=-d A_{p} K\left(\psi-\psi_{\mathrm{s}-\mathrm{f}}\right)
$$

onde $d A_{p}$ é a área superficial total das partículas sólidas num elemento de volume $d V, K$ o coeficiente de transferência de massa, e $\psi_{\text {s-f }}$ a concentração de extrato na interface sólidofluido.

Esta equação é utilizada em processos de transferência de massa (espécies químicas e óleos essências) na fase sólida, a partir de matrizes vegetais, que tem como exemplos, a modelagem matemática do processo de extração com fluido supercrítico de óleo de sálvia (REVERCHON, 1996) e o processo de transferência de massa com fluido supercrítico (LUCAS et al., 2007).

Devido à falta de dados experimentais de equilíbrio de fases (RAI et al., 2014), alguns autores têm adotado uma relação linear do tipo (ROSA et al., 2014; OKIYAMA; RABI, 2013; MELRELES et al., 2009; REVERCHON, 1996):

$$
\phi=k_{p} \psi_{\text {s-f }}
$$

onde $k_{p}$ é o coeficiente de partição volumétrica do extrato, definido na condição de equilíbrio entre a fase sólida e fluida. Nesse sentido, a eq. (2) pode ser reescrita como: 


$$
\dot{\psi}=\frac{\partial \psi}{\partial t}=\frac{1}{t_{i}}\left(\frac{\phi}{k_{p}}-\psi\right), t_{i}=\frac{(1-\varepsilon) d V}{d A_{p} K}
$$

onde $t_{i}$ é tempo de difusão mássica interna. Diversos trabalhos (ROSA et al., 2014; OKIYAMA; RABI, 2013; VARGAS et al., 2006; REVERCHON, 1996) têm avaliado $t_{i}$ a partir das características das partículas. Villermaux (1987) mostrou uma equivalência entre a difusividade intrapartícula e o tempo de difusão mássica interna para diferentes geometrias de partículas, através da eq. (5):

$$
t_{i}=\frac{\mu_{p} l_{p}^{2}}{D_{i}}
$$

onde $\mu_{\mathrm{p}}$ é um coeficiente adimensional que depende da geometria (formato da partícula), $l_{p}$ é um comprimento característico e $D_{i}$ é a difusividade mássica interna (intrapartícula).

As concentrações de extrato na fase fluida também variam com o tempo $t \mathrm{e}$ com a coordenada axial $z$ do leito, de modo que $\phi=\phi(z, t)$. Sabe-se que o transporte de extrato ocorre tanto por difusão como por convecção, através de um balanço de massa temse EDP para concentração na fase fluida $\phi$ (ROSA et al., 2014; OKIYAMA; RABI, 2013):

$$
\varepsilon \frac{\partial \phi}{\partial t}+\bar{v} \frac{\partial \phi}{\partial z}=D \frac{\partial^{2} \phi}{\partial z^{2}}-(1-\varepsilon) \dot{\psi}
$$

onde $\dot{\psi}=\partial \psi / \partial t$ é a taxa de transferência de extrato na fase sólida e $D$ é a difusividade mássica axial, suspostamente uniforme (NIELD; BEJAN, 1999). Alguns modelos têm desprezado esta difusividade (SOVOVÁ, 1994; FRANÇA; MEIRELLES, 2000), mesmo sendo importante em equipamentos de grande porte (REIS-VASCO et al., 2000; GASPAR et al., 2003).

\subsection{Condições iniciais e de contorno}

A habilidade de impor as condições iniciais e de contorno aos modelos matemáticos é de extrema importância. O uso equivocado pode deixar de representar o processo em estudo. Neste trabalho são impostas duas condições iniciais e de contorno, respectivamente.

Sabendo que as equações para concentração de extrato na fase sólida e fluida possuem termos com dependência temporal, aplicam-se as condições iniciais (em $t=0)$ para 
$(0 \leq z \leq L)$. Na fase sólida admite-se que a concentração inicial de extrato é máxima, isto é, toda quantidade de extrato expressa em $\left(\mathrm{kg} / \mathrm{m}^{3}\right)$ encontra-se no interior da partícula (grão de café). Enquanto na fase fluida a concentração inicial de extrato é zero, tendo em vista que o processo de pressurização foi rápido o suficiente a fim de minimizar o transporte de extrato para fase fluida. Tais condições são expressas matematicamente por (ROSA et al., 2014; OKIYAMA; RABI, 2013):

$$
\phi(z, 0)=0 \quad \text { e } \quad \psi(z, 0)=\psi_{\max }
$$

Com relação à geometria do modelo, as condições de contorno para $(t>0)$ são impostas apenas para as concentrações na fase fluida, pois não há derivadas com relação à coordenada $z$ na eq. (4), que descreve as concentrações na fase sólida (OKIYAMA; RABI, 2013). Na entrada do extrator em $z=0$ é imposta uma condição nula de Dirichlet, ou seja, a concentração de extrato na fase fluida (parte superior do leito) é conhecida. Na saída em $z=L$ é imposta uma condição nula de Neumann, considerando-se que o leito é longo o suficiente para que o perfil de concentração esteja desenvolvido (RABI, 2011). Outros trabalhos têm utilizado estas condições (OKIYAMA; RABI, 2013; MELRELES et al., 2009), as quais são expressas matematicamente por:

$$
\phi(0, t)=0 \quad \text { e }\left.\frac{\partial \phi}{\partial t}\right|_{z=L}=0
$$




\section{SIMULAÇÃO COMPUTACIONAL VIA LBM}

Neste capítulo constam a simulação computacional via método lattice Boltzmann em uma dimensão, utilizado no simulador para predizer às extrações das espécies químicas em sistemas de alta pressão, a fundamentação teórica do método lattice Boltzmann, a solução numérica via LBM e a implementação da técnica do gradiente descendente para ajuste dos parâmetros $\left(D_{i}, D\right.$ e $\left.k_{P}\right)$, com uso de dados experimentais.

\subsection{Introdução}

Os modelos matemáticos para os processos de extrações são complexos (GOTO et al., 1993; REVERCHON, 1996; REVERCHON; MARRONE, 1997; SUBRA et al., 1998; CAMPOS et al., 2005) de modo que se tornam necessários o uso de métodos numéricos (MARTINEZ et al., 2007).

Segundo Mohamad (2011), o método lattice Boltzmann foi introduzido por McNamara e Zanetti em 1988, com o propósito de superar os inconvenientes dos modelos de gás em rede ("lattice gas cellular automata”, LGCA), desde então se tornou um método alternativo para simular a mais complexa dinâmica dos fluidos. De acordo com Chen e Doolen (1998), o LBM é um método numérico baseado em equações formuladas em uma escala mesoscópica, que simula a dinâmica de fluidos em uma escala macroscópica.

\subsection{Método lattice Boltzmann}

\subsubsection{Escalas de modelagem e simulação computacional}

De um modo geral, a descrição de um fluido é feita através da mecânica continua. Para isso, utiliza-se a abordagem macroscópica e uso de equações diferenciais, como exemplos, a equação de Euler e da equação de Navier-Stokes (LANDAU, 1982). Para simulação computacional tem-se empregado o método de elementos finitos (MEF), de volumes finitos (MVF) e de diferenças finitas (MDF).

Outra maneira é a abordagem microscópica, com a aplicação das leis de Newton a cada partícula. Esta técnica computacional é conhecida como dinâmica 
molecular. A fim de conhecer as propriedades macroscópicas de interesse (pressão, densidade, temperatura, etc.), usam-se as aplicações da mecânica estatística.

Além destas escalas de modelagem e simulação, é possível representar um fluido através de uma abordagem mesoscópica. Nesta escala, não se busca analisar o comportamento individual das partículas, mas sim, o efeito global de um conjunto de partículas (MOHAMAD, 2011). Nesse contexto, o método lattice Boltzmann tem sido empregado para simulação de uma infinidade de escoamentos.

\subsubsection{Dinâmica das partículas}

Em simulações com o método lattice Boltzmann (LBM), o sistema seja ele sólido ou fluido, é tratado como um conjunto de partículas fictícias habitando um espaço discreto, isto é, os sítios da rede, igualmente fictício. Estas partículas obedecem a dois processos básicos, denominados propagação e colisão, os quais ocorrem durante intervalos discretos de tempo (ROSA et al., 2014; RABI, 2011; SANTOS, 2000).

Na propagação, as partículas vão de um sítio ao vizinho ao longo de direções pré-definidas, ou seja, nas conexões da rede, conforme um conjunto finito de velocidades. Ao chegarem a estes sítios, as partículas colidem entre si de modo a conservar tanto o seu número (massa) como a quantidade de movimento e, assim, suas velocidades são reordenadas (ROSA et al., 2014; RABI, 2011; SANTOS, 2000).

Contudo, ao impor princípios de conservação (massa e quantidade de movimento) para essa dinâmica de partículas, o comportamento médio macroscópico pode ser simulado (WOLF-GLADROW, 2000; SUCCI, 2001).

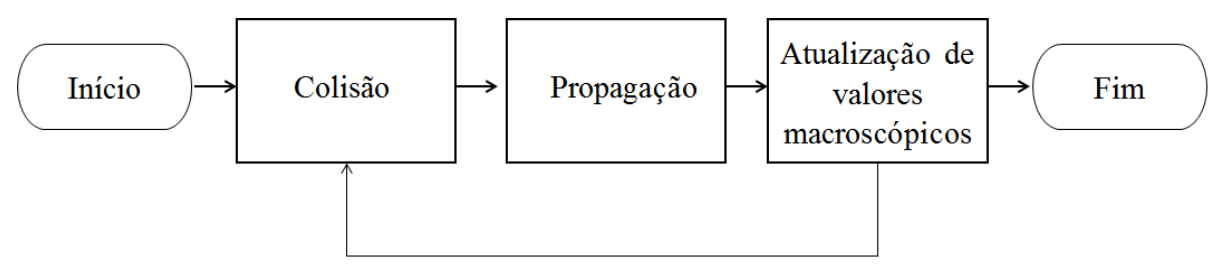

Figura 5. Etapas da simulação computacional via LBM.

\subsubsection{Equação de Boltzmann}

A atuação de uma força externa $F$, durante um intervalo de tempo $d t$, sobre uma partícula de massa $m$, é capaz de alterar sua posição de $\vec{r}$ para $\vec{r}+d \vec{r}$ e a sua 
velocidade de $\vec{c}$ para $\vec{c}+\vec{a} d t$. Como o LBM lida com o comportamento de um conjunto de partículas expressa através da função de distribuição de partículas $f=f(\vec{r}, \vec{c}, t)$, nesse sentido a equação de Boltzmann será apresentada (MOHAMAD, 2011).

Em uma rede com ocorrência de colisões entre partículas, ocorrerá variação na quantidade de moléculas no intervalo $d \vec{r} d \vec{c}$, a taxa de variação da função de distribuição pode ser expressa com a introdução do operador de colisão $\Omega$ (MOHAMAD, 2011):

$$
f(\vec{r}+\vec{c} d t, \vec{c}+\vec{a} d t, t+d t) d \vec{r} d \vec{c}-f(\vec{r}, \vec{c}, t) d \vec{r} d \vec{c}=\Omega(f) d \vec{r} d \vec{c}
$$

Dividindo a Eq. (9) por $d \vec{r} d \vec{c} d t$ de modo que $d t \rightarrow 0$, tem-se:

$$
\frac{d f}{d t}=\Omega(f)
$$

A Eq. (10) afirma que a taxa de variação da função de distribuição é igual à taxa de colisão (MOHAMAD, 2011). Uma vez que $f=f(\vec{r}, \vec{c}, t)$, o diferencial $d f$ por ser expresso como:

$$
d f=\frac{\partial f}{\partial \vec{r}} \cdot d \vec{r}+\frac{\partial f}{\partial \vec{c}} \cdot d \vec{c}+\frac{\partial f}{\partial t} d t
$$

Dividindo a Eq. (11) por $d t$, tem-se:

$$
\frac{d f}{d t}=\frac{\partial f}{\partial \vec{r}} \cdot \vec{c}+\frac{\partial f}{\partial \vec{c}} \cdot \frac{\vec{F}}{m}+\frac{\partial f}{\partial t}
$$

A igualdade entre as Eqs. (10) e (12), tem-se a equação de transporte de Boltzmann:

$$
\frac{\partial f}{\partial t}+\cdot \vec{c} \vec{\nabla} f+\frac{\vec{F}}{m} \frac{\partial f}{\partial c}=\Omega(f)
$$

Na ausência de atuação de forças externas a equação de Boltzmann por ser expressa como:

$$
\frac{\partial f}{\partial t}+\vec{c} \cdot \vec{\nabla} f=\Omega(f)
$$

onde o operador de colisão $\Omega=\Omega(f)$ fornece a taxa de variação da função distribuição devido à colisão entre as partículas. A resolução da Eq. (14) não é trivial. 
As grandezas que caracterizam o estado macroscópico como densidade do fluido $(\rho)$, velocidade de escoamento $(\vec{v})$ e energia interna $(\mu)$ podem ser determinadas a partir da função de distribuição $f(\vec{r}, \vec{c}, t)$ (RABI, 2011; VAN DER SMAN, 2007).

$$
\begin{gathered}
\rho(\vec{r}, t)=\int f(\vec{r}, \vec{c}, t) d \vec{c} \\
\rho(\vec{r}, t) \vec{v}(\vec{r}, t)=\int \vec{c} f(\vec{r}, \vec{c}, t) d \vec{c} \\
\rho(\vec{r}, t) \mu(\vec{r}, t)=\int \frac{1}{2} v_{0}{ }^{2} \vec{c} f(\vec{r}, \vec{c}, t) d \vec{c}
\end{gathered}
$$

onde $v_{0}$ é a velocidade peculiar, definida como a diferença entre a velocidade da partícula $(\vec{c})$ e a velocidade do escoamento $(\vec{v})$, como demonstrado na Eq. (18) (MOHAMAD; RABI, 2011):

$$
\vec{v}_{0}=\vec{c}-\vec{v}
$$

\subsubsection{Aproximação BGK}

A resolução da equação de Boltzmann não é trivial, o operador de colisão $\Omega$ depende da função de distribuição $f$. Com intuito de simplificar o operador de colisão, utiliza-se a aproximação BGK através da relação linear:

$$
\Omega(f)=\frac{f^{e q}-f}{\Delta t_{\text {relax }}}
$$

onde $\Delta t_{\text {relax }}$ é o tempo de relaxação (grandeza de tempo entre as colisões) e $f^{e q}$ é a função de distribuição de equilíbrio local (QIAN; D'HUMIÈRES; LALLEMAND, 1992). Com a relação linear da aproximação BGK, a Eq. (14) assume a forma:

$$
\frac{\partial f}{\partial t}+\vec{c} \cdot \vec{\nabla} f=\frac{f^{e q}-f}{\Delta t_{\text {relax }}}
$$

Ressalta-se que a simplificação do operador de colisão é realizada tendo em vista que o resultado da colisão entre duas partículas não é capaz de alterar significativamente os valores das grandezas medidas (MOHAMAD, 2011). 


\subsubsection{Estruturas de rede}

A ideia básica do LBM é resolver numericamente a Eq. (20) escrita em termos de uma rede fictícia. As diferentes estruturas de rede são identificadas por $\mathrm{D} n \mathrm{Q} m$, com $n$ representando a dimensão do problema, enquanto $m$ corresponde ao modelo de velocidade da rede. Neste trabalho optou-se por uma estrutura de rede do tipo D1Q2, composta por um sítio central ligado a dos sítios vizinhos por uma conexão.

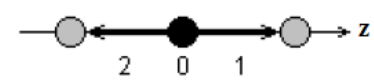

Figura 6. Rede D1Q2 para simulação via LBM

Fonte: RABI, 2011.

Para rede D1Q2 tem-se os vetores velocidades $\left(c_{1}\right.$ e $\left.c_{2}\right)$, para cada sentido de propagação, onde $c_{1}=\Delta z / \Delta t$ e $c_{2}=-\Delta z / \Delta t$. No sítio central a velocidade é nula.

Existem outros tipos de rede para simulação via LBM, as mais comuns em duas dimensões (2D) são: D2Q4 ou D2Q5, D2Q8 ou D2Q9. Em três dimensões (3D) são: D3Q14 ou D3Q15, D3Q18 ou D3Q19.

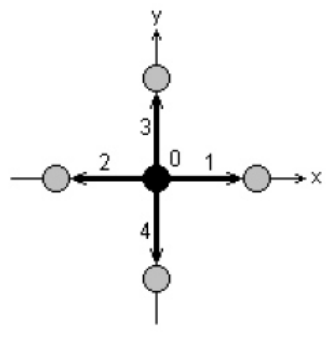

(a)

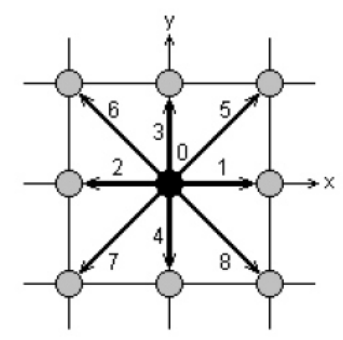

(b)

Figura 7. a) Rede D2Q4 ou D2Q5, b) D2Q8 ou D2Q9

Fonte: RABI, 2011.

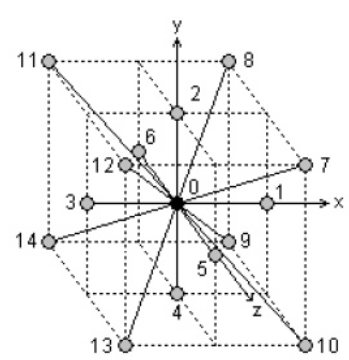

(a)

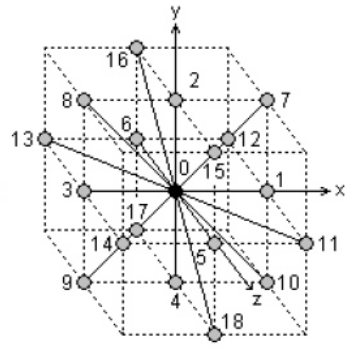

(b)

Figura 8. a) Rede D3Q14 ou D3Q15, b) D3Q18 ou D3Q19 Fonte: RABI, 2011. 


\subsubsection{Discretização da equação de Boltzmann}

O modelo matemático utilizado para representar o transporte de massa é descrito em 1D, ou seja, apenas em uma dimensão, mais especificamente ao longo do eixo z. Portanto, a equação de Boltzmann com a aproximação BGK, discretizada no espaço e no tempo assume a seguinte forma (RABI, 2011):

$$
\frac{f_{k}(z, t+\Delta t)-f_{k}(z, t)}{\Delta t}+c_{k} \frac{f_{k}\left(z+\Delta z_{k}, t+\Delta t\right)-f_{k}(z, t+\Delta t)}{\Delta z_{k}}=\frac{f_{k}^{e q}(z, t)-f_{k}(z, t)}{\Delta t_{\text {relax }}}
$$

onde $c_{k}=\Delta z_{k} / \Delta t \quad\left(\Delta z_{k}= \pm \Delta z\right.$, dependendo do sentido de propagação). Introduzindo o parâmetro de relaxação $\omega=\Delta \mathrm{t} / \Delta \mathrm{t}_{\text {relax }}$ na Eq. (21), obtém-se:

$$
f_{k}\left(z+\Delta z_{k}, t+\Delta t\right)=[1-\omega] f_{k}(z, t)+\omega f_{k}^{e q}(z, t)
$$

Para rede D1Q2 a Eq. (22) precisa ser escrita apenas para $k=1$ e $k=2$, isto é, para as funções $f_{1}$ e $f_{2}$ respectivamente. De acordo com Mohamad (2011), a evolução computacional do algoritmo LBM consiste em duas etapas, colisão e propagação, em consonância com a dinâmica das partículas.

$\mathrm{Na}$ etapa de colisão, as funções de distribuição $f_{k}$, para cada direção $k$, são atualizadas nos sítios da rede de acordo com a Eq. (23):

$$
f_{k}(z, t+\Delta t)=[1-\omega] f_{k}(z, t)+\omega f_{k}^{e q}(z, t)
$$

Na etapa de propagação, os resultados das colisões são transportados aos sítios adjacentes de acordo com a Eq. (24):

$$
f_{k}\left(z+\Delta z_{k}, t+\Delta t\right)=f_{k}(z, t+\Delta t)
$$

A conexão entre a dinâmica das partículas (mesoescala) e o fenômeno de transporte (macroescala) é estabelecida pela função de distribuição de equilíbrio $f^{q}$ e o parâmetro de relaxação $\omega$ (ROSA et al., 2014; MOHAMAD, 2011). Em simulações via LBM, a função de distribuição de equilíbrio governa a natureza do fenômeno de transporte (massa, energia ou quantidade de movimento), enquanto o parâmetro de relaxação $\omega$ determina o valor do coeficiente de transporte (difusividade mássica, difusividade térmica ou viscosidade cinemática) (ROSA et al., 2014; RABI, 2011). 


\subsection{Simulador LBM}

\subsubsection{Introdução}

O simulador LBM foi implementado na linguagem Python pelo autor deste trabalho de pesquisa, a partir de uma versão anterior na linguagem Fortran 90/95 (OKIYAMA; RABI, 2013). A linguagem de programação Python foi criada por Guido van Rossum, no Instituto Nacional de Pesquisa para Matemática e Ciência da Computação da Holanda, em 1991. Possui diversas estruturas de alto de nível, suporta programação modular, funcional e orientação a objetos, além de possuir um modelo de desenvolvimento comunitário, aberto e gerenciado pela organização sem fins lucrativos Python Software Foundation (BURIOL; ARGENTA, 2009).

Destaca-se que o simulador LBM foi implementado em outras linguagem de programação, como exemplo MatLab R2012a. Comparações de desempenho no que se refere ao tempo de processamento, interface com usuário e interface gráfica entre tais linguagens, foram realizadas e serão divulgadas em publicações posteriores.

\subsubsection{Solução numérica do método}

\subsubsection{Funções de distribuição de partículas}

Assim como proposto no modelo fenomenológico, nas simulações via LBM as espécies químicas (cafestol e caveol) são independentes e as extrações foram modeladas a partir das Eqs. (2) a (8). As funções de distribuição de partículas $f_{k}=f_{k}(z, t)$ e $s_{k}=s_{k}(z, t)$ foram atribuídas às concentrações de extrato nas fases fluida e sólida, respectivamente. Usando a rede D1Q2, as concentrações de extrato podem ser determinadas em qualquer tempo $t$ e posição $z$, através das Eqs. (25) e (26) (ROSA et al., 2014):

$$
\begin{aligned}
& \phi(z, t)=\sum_{k} f_{k}(z, t)=f_{1}(z, t)+f_{2}(z, t) \\
& \psi(z, t)=\sum_{k} s_{k}(z, t)=s_{1}(z, t)+s_{2}(z, t)
\end{aligned}
$$

Nas simulações via método lattice Boltzmann, os termos fonte e sumidouro são introduzidos no lado direto da Eq. (23), desse modo, as expressões para as funções de 
distribuição na fase sólida e fluida assumem a forma das Eqs. (27) e (28), respectivamente, para etapa de colisão (ROSA et al., 2014).

$$
\begin{gathered}
s_{k}(z, t+\Delta t)=\left[1-\omega_{\mathrm{s}}\right] s_{k}(z, t)+\omega_{\mathrm{s}} s_{k}^{\mathrm{eq}}(z, t)+w_{k} \dot{S}_{\mathrm{s}} \Delta t \\
f_{k}(z, t+\Delta t)=\left[1-\omega_{\mathrm{f}}\right] f_{k}(z, t)+\omega_{\mathrm{f}} f_{k}^{\mathrm{eq}}(z, t)+w_{k} \dot{S}_{\mathrm{f}} \Delta t
\end{gathered}
$$

Em consonância com a Eq. (4), proposta no modelo fenomenológico, o termo sumidouro foi implementado para as funções de distribuição de partículas na fase sólida como (ROSA et al., 2014):

$$
\dot{S}_{\mathrm{s}}=-\frac{1}{t_{\mathrm{i}}}\left(\psi-\frac{\phi}{k_{\mathrm{P}}}\right)(<0)
$$

De forma análoga, em consonância com a Eq. (6), proposta no modelo fenomenológico, o termo fonte foi implementado para funções de distribuição de partículas na fase fluida como (ROSA et al., 2014):

$$
\dot{S}_{f}=\frac{\frac{1}{t_{\mathrm{i}}}\left(\psi-\frac{\phi}{k_{\mathrm{P}}}\right)(1-\varepsilon)}{\varepsilon}(>0)
$$

Como a Eq. (4) não apresenta derivadas com relação à coordenada $z$, foi possível suprimir a etapa de propagação, referente às funções de distribuição na fase sólida $\left(s_{k}\right)$ no código LBM (ROSA et al., 2014; RABI; MOHAMAD, 2008). Consequentemente, a propagação foi executada somente para as funções de distribuição na fase fluida $\left(f_{k}\right)$ em concordância com a Eq. (24).

Para rede D1Q2, os coeficientes de ponderação $\left(w_{k}\right)$ são $w_{1}=w_{2}=1 / 2$, obedecendo à condição de normalização previsto na Eq. (31).

$$
\sum_{k} w_{k}=1
$$

Tabela 3. Valores de coeficientes de ponderação $w_{k}$.

\begin{tabular}{|c|c|c|c|c|c|c|}
\hline$\left\|\vec{c}_{k}\right\|^{2}$ & D1Q2 & D1Q3 & D2Q4 & D2Q9 & D3Q15 & D3Q19 \\
\hline 0 & 0 & $4 / 6$ & 0 & $16 / 36$ & $16 / 72$ & $12 / 36$ \\
\hline 1 & $1 / 2$ & $1 / 6$ & $1 / 4$ & $4 / 36$ & $8 / 72$ & $2 / 36$ \\
\hline 2 & - & - & - & $1 / 36$ & - & $1 / 36$ \\
\hline 3 & - & - & - & - & $1 / 72$ & 1 \\
\hline
\end{tabular}

Fonte: Rabi, 2011. 


\subsubsection{Funções de distribuição de equilíbrio}

As funções de distribuição de equilíbrio governam a natureza do fenômeno de transporte (MOHAMAD, 2011). Encontrar tais funções não é trivial, mas se fazem necessárias nos modelos de rede BKG. Contudo, alguns autores propuseram algumas formas gerais para determinação destas funções. Rothman e Zaleski (1997) propuseram uma forma geral nos casos onde o escoamento possui baixa velocidade:

$$
f_{k}^{e q}=A_{k}+B_{k}\left(\vec{c}_{k} \cdot \vec{v}\right)+C_{k}\left(\vec{c}_{k} \cdot \vec{v}\right)^{2}+D_{k}(\vec{v} \cdot \vec{v})
$$

onde $A_{k}, B_{k}, C_{k}$ e $D_{k}$ são coeficientes a serem determinados. Nesse sentido, outros autores como Mohamad (2011), também propuseram uma forma geral para tais funções de equilíbrio, como expresso na Eq. (33):

$$
f_{k}^{e q}=w_{k} \rho\left[1+\frac{\left(\vec{c}_{k} \cdot \vec{v}\right)}{c_{s}{ }^{2}}+\frac{\left(\vec{c}_{k} \cdot \vec{v}\right)^{2}}{2 c_{s}{ }^{4}}+\frac{(\vec{v} \cdot \vec{v})}{2 c_{s}{ }^{2}}\right]
$$

Tendo em vista que na fase fluida ocorram fenômenos de difusão e convecção, a Eq. (33) pode ser expressa para esta fase como (MOHAMAD; RABI, 2011):

$$
f_{k}^{e q}=w_{k} \rho\left[1+\frac{\left(\vec{c}_{k} \cdot \vec{v}\right)}{c_{s}^{2}}\right]
$$

Enquanto a fase sólida permanece estacionária com a ocorrência de difusão pura, a Eq. (33) pode ser expressa para esta fase como (MOHAMAD; RABI, 2011):

$$
f_{k}^{e q}=w_{k} \rho
$$

Nesse sentido, as funções de distribuição de equilíbrio local para fase fluida e sólida podem ser expressas, respectivamente como (ROSA et al., 2014; MOHAMAD, 2011):

$$
\begin{gathered}
f_{k}^{\mathrm{eq}}(z, t)=w_{k} \phi(z, t)\left(1+\frac{v}{c_{k}}\right) \\
\mathrm{s}_{k}^{\mathrm{eq}}(z, t)=w_{k} \psi(z, t)
\end{gathered}
$$

$\operatorname{com} c_{k}= \pm \Delta z / \Delta t$ dependendo da direção da propagação. 


\subsubsection{Parâmetro de relaxação}

Mais uma vez, a conexão entre a dinâmica das partículas e o fenômeno de transporte é estabelecida pelo parâmetro de relaxação $(\omega)$ e a função de distribuição de equilíbrio $\left(f^{e q}\right)$. O parâmetro de relaxação determina o valor do coeficiente de transporte como exemplo a difusividade térmica, a difusividade mássica ou a viscosidade cinemática.

Em processo de transferência de calor, o parâmetro relaxação $(\omega)$ se relaciona com a difusividade térmica $(\alpha)$ através da relação (MOHAMAD, 2011; VAN DER SMAN, 2007):

$$
\alpha=c_{s}{ }^{2}\left(\frac{1}{\omega}-\frac{1}{2}\right) \Delta t \Leftrightarrow \omega=\left(\frac{\alpha}{c_{s}^{2} \Delta t}+\frac{1}{2}\right)^{-1}
$$

De acordo com Rabi (2011), em processos de transferência de massa, ou seja, espécies químicas, a difusividade térmica $(\alpha)$ é substituída pela difusividade mássica $(D)$. Neste trabalho, o transporte de extrato 1-D (axial) é regido pela Eq. (9), portanto, a difusividade mássica na fase fluida $(D)$ e o parâmetro de relaxação $\left(\omega_{\mathrm{f}}\right)$ relacionam-se como (ROSA et al., 2014; OKIYAMA; RABI, 2013):

$$
D=c_{s}^{2}\left(\frac{1}{\omega_{\mathrm{f}}}-\frac{1}{2}\right) \Leftrightarrow \frac{1}{\omega_{\mathrm{f}}}=\frac{D \Delta t}{(\Delta z)^{2}}+\frac{1}{2}
$$

Como a Eq. (4) envolve apenas transporte de difusão, adotou-se $\omega_{\mathrm{s}}=2$ para a fase sólida.

\subsubsection{Condições iniciais e de contorno}

As condições iniciais, isto é, no instante $(t=0)$ para concentrações iniciais de extrato na fase sólida $\psi(z, 0)$ e fluida $\phi(z, 0)$, são fornecidas pelas Eq. (7), ou seja, como proposto no modelo fenomenológico. Nesse sentido, as funções de distribuição de partículas para fase sólida e fluida, são impostas, respectivamente como (ROSA et al., 2014; MOHAMAD, 2011):

$$
s_{k}(z, 0)=w_{k} \psi(z, 0) \quad e \quad f_{k}(z, 0)=w_{k} \phi(z, 0)
$$


As condições de contorno são impostas na entrada do leito $(z=0)$ e na saída em $(z=L)$. Na entrada do leito $(z=0)$, a função de distribuição $f_{2}(0, t)$ é obtida por propagação do sítio adjacente. Como proposto na Eq. (8) do modelo, admite-se que a concentração de extrato na fase é nula, ou seja, $\phi(0, t)=0$, as condições de contorno para $f_{1}(0, t)$ são obtidas por conservação de fluxo, expressas como (ROSA et al., 2014; MOHAMAD, 2011):

$$
f_{1}(0, t)=\phi(0, t)-f_{2}(0, t) \stackrel{\phi(0, t)=0}{\longrightarrow} f_{1}(0, t)=-f_{2}(0, t)
$$

Outra condição de contorno é na saída do leito $(z=L)$, onde a função de distribuição $f_{1}(L, t)$ é obtida por propagação do sítio adjacente, de forma que $f_{2}(L, t)$ é desconhecida. Aproximando a condição nula de Neumann, Eq. (8), através de diferenças finitas de primeira ordem, obtém-se a seguinte condição de contorno (ROSA et al., 2014; MOHAMAD, 2011):

$$
f_{1}(L, t)=f_{1}(L-\Delta z, t)
$$




\subsubsection{Fluxograma}

Baseado no método de diagrama de bloco proposto por Manzano e Oliveira (2010), a Figura (9) ilustra o fluxograma da simulação numérica para extração de espécies químicas via LBM.

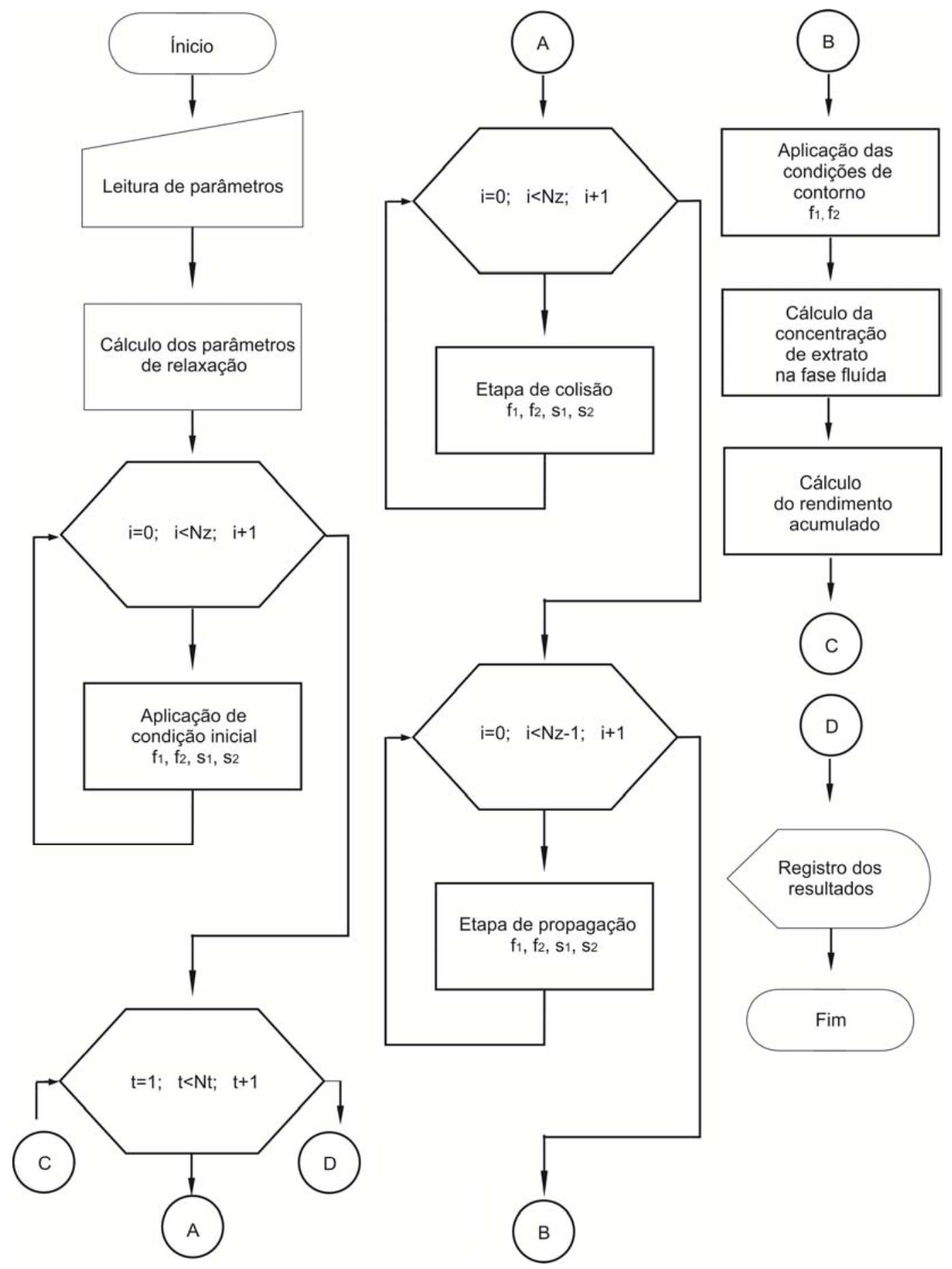

Figura 9. Fluxograma da simulação numérica via LBM. 


\subsection{Ajuste de parâmetros}

Simulações numéricas envolvendo processos de transferência de massa exigem o conhecimento de vários parâmetros; alguns podem ser obtidos com medições diretas, outros precisam ser ajustados contra dados experimentais, com uso de técnicas computacionais de otimização de dados. Dentre as diversas técnicas, destaca-se o uso de ajuste de dados através de diferença quadrática (VARGAS et al., 2006) e o método do gradiente descendente (ROSA et al., 2014).

Neste trabalho, os parâmetros do processo foram classificados em três categorias. Os que dependem diretamente da temperatura de operação, os que não dependem e os auxiliares, inerentes à rede Boltzmann. Aqueles que dependem da temperatura de operação como difusividade intrapartícula $\left(D_{i}\right)$, difusividade mássica axial $(D)$ e coeficiente de partição volumétrica $\left(k_{P}\right)$, foram ajustados com a técnica do gradiente descendente com uso de dados experimentais.

A técnica do gradiente descendente tem sido muito utilizada na resolução de problema de otimização, como na calibração de dados em rede de distribuição radial (AQUINO NETO et al., 2004), na otimização de dados em equipamentos de inspeção (BROWN et al., 2004), na calibração de dados para estudos de confiabilidade em redes de distribuição (FERREIRA, 2010) e na otimização de ambientes dinâmicos com variáveis contínuas (GONCALVES, 2011).

De um modo geral, o algoritmo parte de um ponto inicial para um $\left(D i, k_{P}\right.$ e $\left.D\right)$ determinado pelo usuário e obtém a direção que produz o maior decréscimo (problema de minimização) da função, indicada pela informação contida no seu vetor gradiente (GONÇALVES, 2011). Como tal vetor aponta para a direção de maior crescimento da função, busca-se então caminhar na direção contrária, até que se encontre o menor erro possível (mínimo local). A figura 10 ilustra a técnica do gradiente descendente através de uma superfície de erro. 


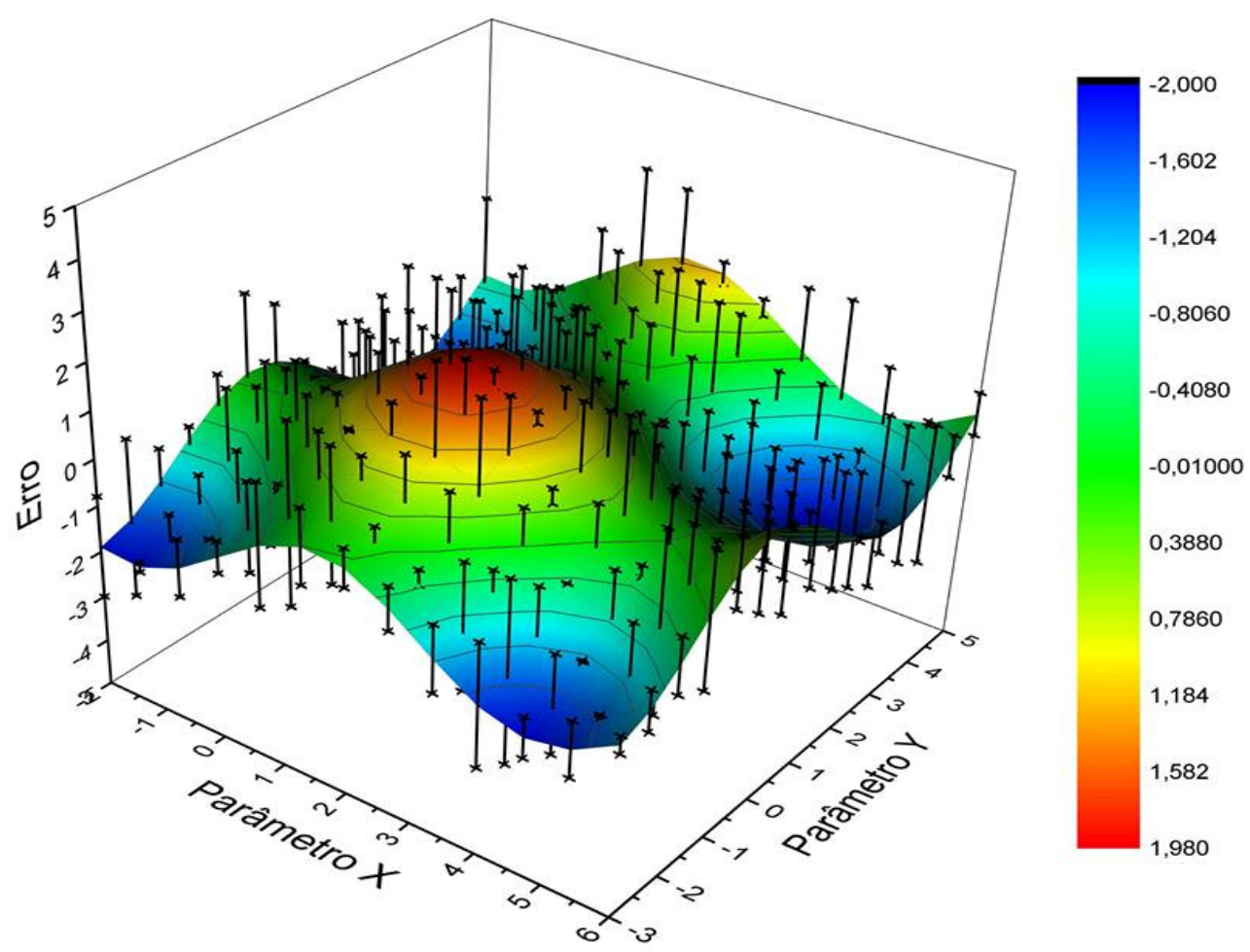

Figura 10. Ilustração de superfície de erro.

Em princípio foi desenvolvido e implementado um código computacional na linguagem de programação python, cujo objetivo foi encontrar valores iniciais de $\left(D_{i}, D\right.$ e $\left.k_{P}\right)$. Este código faz uma varredura de $\left(D_{i}, D\right.$ e $\left.k_{P}\right)$ calculando a diferença quadrática entre as curvas de rendimentos simuladas e a experimental.

O intervalo de varredura para cada parâmetro foi imposto no código computacional, tendo como referência outros trabalhos como Rai et al. (2014), Vargas et al. (2006), Subra et al. (1998) e Reis-Vasco et al. (2000), que ajustaram tais valores para outras espécies químicas. Foi possível a implementação não apenas do intervalo de varredura, mas também do peso de cada parâmetro. Ressalta-se que para o ajuste de $\left(D_{i}, D\right.$ e $k_{P}$ ) através da técnica do gradiente descendente é necessário um ponto de partida para cada parâmetro. Daí, a necessidade de desenvolvimento e implementação deste código inicial.

Em um segundo momento, foi desenvolvido e executado outro código computacional também na linguagem de programação python com a técnica do gradiente descendente. A ideia fundamental desta técnica é encontrar um mínimo local de uma dada função. Neste trabalho, a função a ser minimizada se refere à diferença quadrática entre a curva de rendimento simulada e a experimental. A solução numérica consistiu em 
encontrar os melhores valores para três parâmetros $\left(D_{i}, D\right.$ e $\left.k_{P}\right)$, ou seja, um mínimo local no espaço tridimensional (ROSA et al., 2014). Esta técnica consistiu na elaboração computacional do seguinte algoritmo:

- Atribuição de valores iniciais para $\left(D_{i}, D\right.$ e $\left.k_{P}\right)$, obtidos com código computacional de varredura de parâmetros;

- Atribuição de valores para os incrementos de $\left(D_{i}, D\right.$ e $\left.k_{P}\right)$, ou seja, o tamanho do passo (cujos valores são independentes entre si);

- Atribuição dos valores experimentais da curva de rendimento de extrato;

- Simulação numérica da curva de rendimento via LBM, usando os valores iniciais e posteriormente os seus incrementos;

- Realização do cálculo da diferença quadrática entre a curva de rendimento simulada e a experimental;

- Verificação da direção de menor decréscimo (menor erro);

- Atualização e registros dos parâmetros $\left(D_{i}, D\right.$ e $\left.k_{P}\right)$;

- O algoritmo é repetido até que se encontrem os valores mais apropriados para $\left(D_{i}\right.$, $D$ e $k_{P}$ ), ou seja, um mínimo local.

Baseado no método de diagrama de bloco proposto por Manzano \& Oliveira (2010), a Figura (11) ilustra o fluxograma para o ajustes dos parâmetros $\left(D_{i}, D\right.$ e $\left.k_{\mathrm{P}}\right)$ através da técnica do gradiente descendente. 


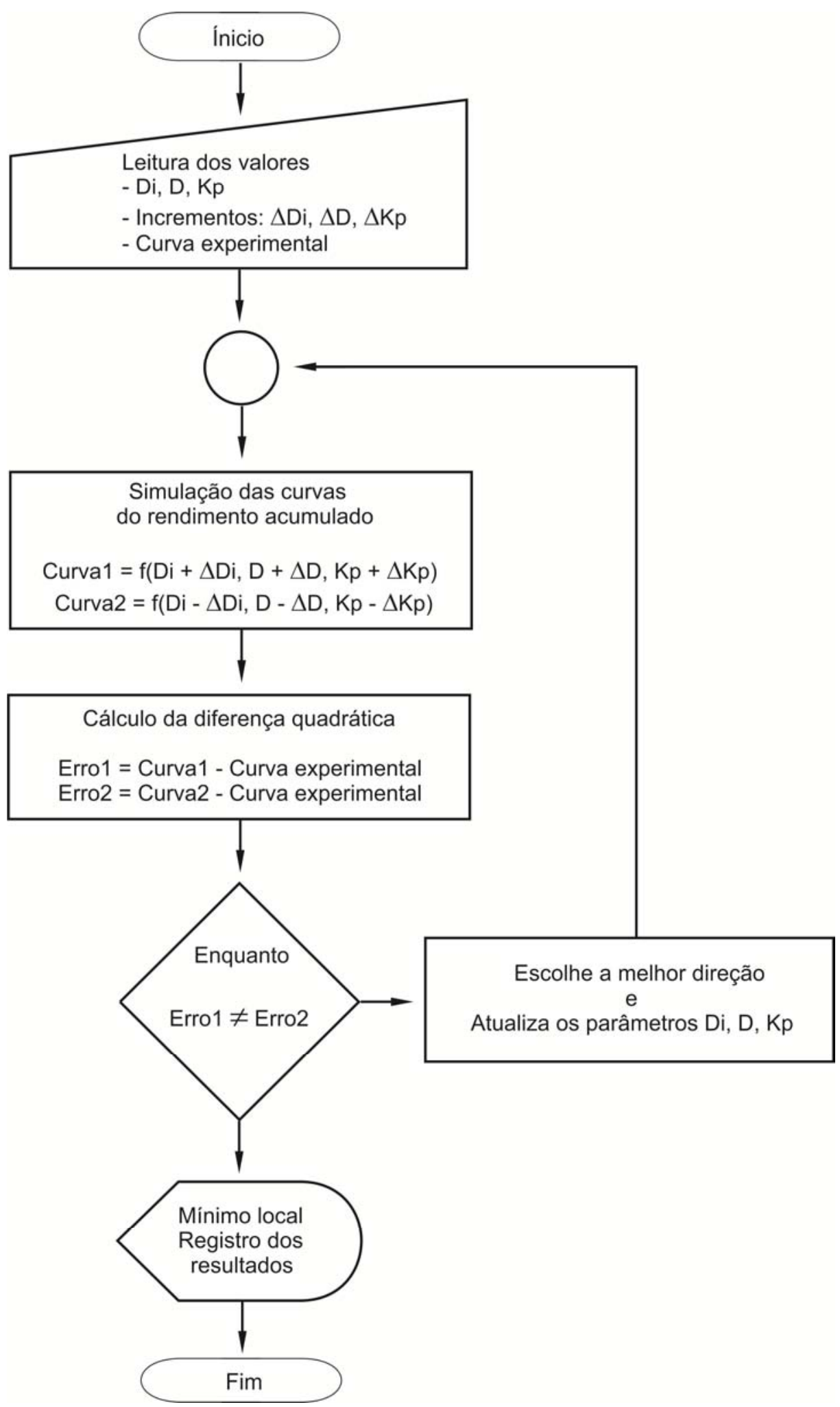

Figura 11. Fluxograma: ajuste dos parâmetros via gradiente descendente. 


\section{ANÁLISE E DISCUSSÃO DOS RESULTADOS}

Neste capítulo constam a caracterização dos parâmetros do processo de extração dos compostos diterpênicos do café verde (caveol e cafestol) com fluido pressurizado, as simulações numéricas via método lattice Boltzmann (LBM), a análise e discussão dos resultados.

\subsection{Caracterização de parâmetros}

São considerados parâmetros de extração as variáveis que influenciam os resultados dessas extrações, em termos de rendimentos (FILIPPIS, 2001). Como já foi mencionando, os parâmetros necessários para as simulações numéricas das espécies químicas via LBM podem ser divididos em três categorias.

Tabela 4. Classificação dos parâmetros de simulação via LBM.

\section{I - Independentes da temperatura}

\begin{tabular}{c|c|c}
\hline Descrição & Símbolo & Unidade \\
\hline Raio do leito & $R$ & $\mathrm{~m}$ \\
\hline Comprimento do leito & $L$ & $\mathrm{~m}$ \\
\hline Porosidade do leito & $\varepsilon$ & adimensional \\
\hline Vazão de solvente & $\dot{V}$ & $\mathrm{~m}^{3} / \mathrm{s}$ \\
\hline Comprimento característico da partícula & $l_{p}$ & $\mathrm{~m}$ \\
\hline Coeficiente de formato da partícula & $\mu$ & adimensional \\
\hline
\end{tabular}

\section{II - Dependentes da temperatura}

\begin{tabular}{c|c|c}
\hline Descrição & Símbolo & Unidade \\
\hline Difusividade intrapartícula & $D_{i}$ & $\mathrm{~m}^{2} / \mathrm{s}$ \\
\hline Difusividade mássica axial & $D$ & $\mathrm{~m}^{2} / \mathrm{s}$ \\
\hline Coeficiente de partição volumétrica & $k_{\mathrm{P}}$ & $\mathrm{m}^{3}$ sólido $/ \mathrm{m}^{3} f l u i d o$ \\
\hline
\end{tabular}

\section{III - Auxiliares}

\begin{tabular}{c|c|c}
\hline Descrição & Símbolo & Unidade \\
\hline Distância entre os sítios da rede & $\Delta z$ & $\mathrm{~m}$ \\
\hline Passo de tempo & $\Delta t$ & $\mathrm{~s}$ \\
\hline Número de Mach & $M a$ & adimensional \\
\hline Velocidade do som na rede & $c_{s}$ & $\mathrm{~m} / \mathrm{s}$ \\
\hline
\end{tabular}


Os independentes da temperatura de operação $(L, R, \varepsilon, \dot{V})$ foram determinados através de medições experimentais $\left(l_{p}\right.$ e $\left.\mu\right)$, através de parâmetros já consagrados na literatura. Os dependentes da temperatura de operação $\left(D_{i}, D\right.$ e $\left.k_{P}\right)$ foram ajustados com uso de dados experimentais através da técnica do gradiente descendente. E os auxiliares $(\Delta z, \Delta \mathrm{t}, \mathrm{Ma}$ e $c)$ foram calculados de modo que o número de Mach manteve-se baixo.

Mais uma vez, ressalta-se que os dados experimentais utilizados neste trabalho para validação do modelo, foram disponibilizados pelo Laboratoire de Procédés, da Université d'Orléans. Informações detalhadas sobre as cinéticas de extrações (experimentais) de cafestol e caveol constam no trabalho de Belandria et al. (2014).

Os compostos diterpenos (cafestol e caveol) foram obtidos a partir de amostras de grãos de café verde arábica da região de São Paulo, extraídos em sistema de alta pressão com fluido pressurizado (PFE) e com a utilização do solvente metanol. A quantificação destas substâncias foi através de cromatografia líquida de alta eficiência (HPLC).

\subsubsection{Parâmetros independentes da temperatura}

Neste item consta a caracterização dos parâmetros relacionados ao equipamento de extração e as partículas dos grãos de café verde, os quais não são influenciados diretamente pela temperatura de operação.

\subsubsection{Determinação da porosidade do leito}

A porosidade $(\varepsilon)$ do leito foi determinada pela relação entre a densidade aparente e real, demonstrada na eq. (43):

$$
\mathcal{E}=1-\frac{\rho_{\text {aparente }}}{\rho_{\text {real }}}
$$

onde $\rho_{\text {aparente }}$ é a densidade aparente e $\rho_{\text {real }}$ é a densidade real dos sólidos triturados. As medidas foram obtidas por Oliveira (2013) 
Tabela 5. Medidas experimentais: densidades dos grãos de café verde.

\begin{tabular}{cc}
\hline Descrição & Valor \\
\hline Densidade aparente & $\rho_{\text {aparente }}=0,663 \mathrm{~g} / \mathrm{cm}^{3}$ \\
Densidade real & $\rho_{\text {real }}=1,26 \mathrm{~g} / \mathrm{cm}^{3}$ \\
\hline
\end{tabular}

Fonte: Oliveira, 2013.

\subsubsection{Determinação do coeficiente de formato das partículas}

O coeficiente de formato das partículas é adimensional e foi determinado através das relações de Villermaux (1987). A cada geometria de partícula é atribuído um valor específico. Diversos modelos têm utilizado essas relações (OKIYAMA; RABI, 2013; VARGAS et al., 2006). Neste trabalho, grãos de café verde foram considerados como partículas esféricas.

Tabela 6. Valores dos coeficientes de formato das partículas.

\begin{tabular}{cc}
\hline Descrição & Valor \\
\hline Partículas esféricas & $\mu=3 / 5$ \\
Partículas cilíndricas & $\mu=1 / 2$ \\
Partículas planares & $\mu=1 / 3$ \\
\hline
\end{tabular}

Fonte: Villermaux, 1987.

\subsubsection{Determinação do comprimento característico das partículas}

O comprimento característico das partículas $\left(l_{\mathrm{p}}\right)$ foi determinado pela Eq. (44), proposto por Villermaux (1987):

$$
l_{p}=\frac{r}{3}
$$

onde $r$ é o raio médio da partícula. Esta medida foi obtida por Oliveira (2013).

Tabela 7. Medida experimental: raio médio dos grãos de café verde.

\begin{tabular}{cc}
\hline Descrição & Valor \\
\hline Raio médio das partículas & $r=4,80 \times 10^{-4} \mathrm{~m}$ \\
\hline
\end{tabular}

Fonte: Oliveira, 2013. 


\subsubsection{Determinação da concentração máxima de extrato na fase sólida}

A concentração máxima de extrato na fase sólida $\left(\psi_{\max }\right)$ é um parâmetro de grande relevância na simulação via LBM. Ele especifica a quantidade da espécie química, expressa em unidades de massa por volume, disponível nos grãos de café. Alguns fatores podem influenciá-lo como, por exemplos: a genética da planta do café; a forma de armazenamento; o acondicionamento dos grãos; o processo de extração ou até mesmo o método de quantificação. Esta concentração máxima foi determinada através da eq. (45):

$$
\psi_{\max }=\frac{m_{\text {extrato }}}{m_{\text {total }}} \times \rho_{\text {real }}
$$

onde $m_{\text {extrato }}$ é a massa de extrato (espécie química) armazenada na fase sólida. A massa de extrato foi obtida experimentalmente por Belandria et al. (2014), através das cinéticas com melhores rendimentos, ou seja, extração via PFE com uso de solvente metanol e temperatura de $100^{\circ} \mathrm{C}$.

Tabela 8. Medidas experimentais: massa de extrato na fase sólida.

\begin{tabular}{cc}
\hline Descrição & Valor \\
\hline Massa de extrato na fase sólida (caveol) & $m_{\text {extrato }}=137,95 \mathrm{mg}$ \\
Massa de extrato na fase sólida (cafestol) & $m_{\text {extrato }=} 92,97 \mathrm{mg}$ \\
\hline
\end{tabular}

Fonte: Belandria et al., 2014.

\subsubsection{Resultados parciais}

Os parâmetros relacionados ao equipamento de extração como, por exemplos, o comprimento do leito e o diâmetro do leito, foram obtidos experimentalmente por Oliveira (2013). A massa total de grãos de café verde no leito e o raio médio das partículas foram obtidos também por Oliveira (2013). A vazão de solvente foi pré definida no equipamento de extração. Os dados estão dispostos na tabela 7. 
Tabela 9. Parâmetros independentes da temperatura.

\begin{tabular}{cc}
\hline Descrição & Valor \\
\hline Comprimento do leito & $L=0,006 \mathrm{~m}$ \\
Raio interno do leito & $R=0,040 \mathrm{~m}$ \\
Porosidade do leito & $\varepsilon=0,474$ \\
Vazão volumétrica de solvente (metanol) & $\dot{V}=5,0 \times 10^{-8} \mathrm{~m}^{3} / \mathrm{s}$ \\
Massa total da amostra & $\mathrm{m}_{\text {total }}=0,020 \mathrm{~kg}$ \\
Coeficiente de formato das partículas & $\mu=3 / 5$ \\
Comprimento característico das partículas & $l_{p}=4,8 / 3 \times 10^{-4} \mathrm{~m}$ \\
Concentração de extrato na fase sólida (caveol) & $\Psi_{\max }=8,690 \mathrm{~kg} / \mathrm{m}^{3}$ \\
Concentração de extrato na fase sólida (cafestol) & $\Psi_{\max }=5,813 \mathrm{~kg} / \mathrm{m}^{3}$
\end{tabular}

Fonte: Rosa et al., 2014.

\subsubsection{Parâmetros dependentes da temperatura}

Os parâmetros do processo relacionado ao mecanismo de transferência de massa, como difusividade intrapartícula $\left(D_{i}\right)$, difusividade mássica axial $(D)$ e coeficiente de partição volumétrica $\left(k_{\mathrm{P}}\right)$, foram ajustados com o método de gradiente descendente com uso de dados experimentais.

Para cada cinética de extração foi possível encontrar os melhores valores para $D_{i}, D$ e $k_{\mathrm{P}}$. Apesar da escassez de dados na literatura sobre tais valores, a técnica do gradiente descendente encontrou resultados satisfatórios.

Tabela 10. Extração de caveol: parâmetros do processo ajustáveis.

\begin{tabular}{|c|c|c|c|}
\hline \multirow[t]{2}{*}{ Descrição } & \multicolumn{3}{|c|}{ Temperatura } \\
\hline & $60^{\circ} \mathrm{C}$ & $80^{\circ} \mathrm{C}$ & $100^{\circ} \mathrm{C}$ \\
\hline Difusividade mássica intrapartícula $D_{\mathrm{i}}\left(10^{-11} \mathrm{~m}^{2} / \mathrm{s}\right)$ & 1,20 & 0,795 & 0,905 \\
\hline $\begin{array}{l}\text { Coeficiente de partição volumétrica } \mathrm{k}_{\mathrm{P}} \\
\qquad\left(\mathrm{m}^{3} \text { sólido } / \mathrm{m}^{3} \text { fluido }\right)\end{array}$ & 0,280 & 0,390 & 0,410 \\
\hline Difusividade mássica axial $D\left(10^{-8} \mathrm{~m}^{2} / \mathrm{s}\right)$ & 3,60 & 0,395 & 0,110 \\
\hline
\end{tabular}

Fonte: Rosa et al., 2014. 
Tabela 11. Extração de cafestol: parâmetros do processo ajustáveis.

\begin{tabular}{cccc}
\hline Descrição & \multicolumn{3}{c}{ Temperatura } \\
& $\mathbf{6 0}^{\mathbf{0}} \mathbf{C}$ & $\mathbf{8 0}^{\mathbf{0}} \mathbf{C}$ & $\mathbf{1 0 0}^{\mathbf{0}} \mathbf{C}$ \\
\hline Difusividade mássica intrapartícula $D_{\mathrm{i}}\left(10^{-11} \mathrm{~m}^{2} / \mathrm{s}\right)$ & 1,20 & 1,10 & 1,00 \\
Coeficiente de partição volumétrica $\mathrm{k}_{\mathrm{P}}$ & & & \\
$\quad\left(\mathrm{m}^{3}\right.$ sólido/m $/ \mathrm{m}^{3}$ fluido) & 0,290 & 0,350 & 0,450 \\
$\quad$ Difusividade mássica axial $D\left(10^{-8} \mathrm{~m}^{2} / \mathrm{s}\right)$ & 4,30 & 2,70 & 0,150 \\
\hline
\end{tabular}

Fonte: Rosa et al., 2014.

\subsubsection{Parâmetros auxiliares}

Em simulações numéricas via LBM, é necessário escolher adequadamente os parâmetros auxiliares como distância entre os sítios da rede $(\Delta z)$ e o passo de tempo $(\Delta t)$, pois acarretará diretamente no número de Mach $(M a)$ e na velocidade do som na rede $\left(c_{s}\right)$.

A fim de garantir um baixo número de Mach nas simulações, isto é, $M a<0.1$ (MOHAMAD, 2011), adotou-se $\Delta z=1,0 \times 10^{-4} \mathrm{~m}$ (distância uniforme entre os sítios da rede) e $\Delta t=0,1 \mathrm{~s}$ (passo de tempo).

\subsubsection{Determinação da velocidade do som na rede}

Segundo Rabi (2011), em simulações via LBM e com o uso de rede D1Q2, a velocidade do som na rede $\left(c_{s}\right)$ se relaciona com a velocidade das partículas $c=\Delta z / \Delta t$, da seguinte maneira:

$$
c_{s}^{2}=c^{2}
$$

\subsubsection{Determinação do número de Mach}

O número de Mach foi determinado pela relação entre a velocidade intersticial e a velocidade do som na rede, demonstrado na eq. (47):

$$
M a=\frac{v}{c_{s}}
$$




\subsubsection{Resultados parciais}

Na tabela 10 constam os parâmetros auxiliares para as simulações numéricas via LBM executadas neste trabalho de pesquisa.

Tabela 12. Parâmetros auxiliares.

\begin{tabular}{cc}
\hline Descrição & Valor \\
\hline Distância entre os sítios da rede & $\Delta z=1,0 \times 10^{-4} \mathrm{~m}$ \\
Passo de tempo & $\Delta t=0,1 \mathrm{~s}$ \\
Número de Mach & $M a=0,02099$ \\
Velocidade do som na rede & $c_{s}=1,0 \times 10^{-3} \mathrm{~m} / \mathrm{s}$ \\
Velocidade intersticial & $v=2,099 \times 10^{-5} \mathrm{~m} / \mathrm{s}$ \\
\hline
\end{tabular}

Fonte: Rosa et al., 2014.

\subsection{Simulações numéricas}

Após a caracterização dos parâmetros nas simulações via LBM, buscou-se simular numericamente as curvas de concentração de extrato na fase fluida (junto à saída do leito) e as curvas de rendimento acumulado. Para isso, as EDPs para fase sólida e fluida Eqs. (4) e (6), respectivamente, bem como as condições inicias e de contorno Eqs. (7) e (8), (ROSA et al., 2014; OKIYAMA; RABI, 2013) previstas no modelo fenomenológico, foram devidamente resolvidas nas simulações LBM.

A curva de rendimento acumulado $\mathrm{Y}=\mathrm{Y}(\mathrm{t})$ foi obtida a partir da integral da curva de concentração de extrato na fase fluida, conforme demonstra Eq. (48) (ROSA et al., 2014; OKIYAMA; RABI, 2013):

$$
Y(t)=\frac{1}{m_{\text {total }}} \int_{0}^{t} m_{\text {extrato,sai }} d t^{\prime}=\frac{1}{m_{\text {total }}} \int_{0}^{t} \dot{V} \phi_{\text {sai }} d t^{\prime}=\frac{\dot{V}}{m_{\text {total }}} \int_{0}^{t} \phi\left(L, t^{\prime}\right) d t^{\prime}
$$

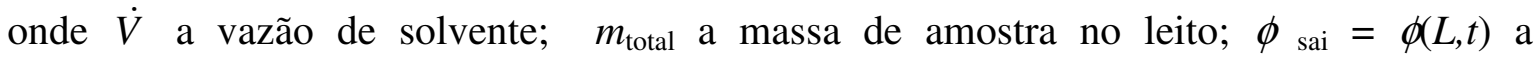
concentração de extrato na fase fluida, que abandona o extrator na posição $L$ no tempo $t$.

\subsubsection{Curvas de concentração de extrato na fase fluida}

As figuras (12) e (13) exibem as concentrações de extrato na fase fluida (simuladas via LBM, na saída do leito) para as espécies químicas cafestol e caveol, 
respectivamente. Estas figuras (e figuras subsequentes) foram geradas em ambiente python que impede o uso de caracteres especiais. Assim e tendo em mente a publicação destes resultados (ROSA et al., 2014), optou-se aqui por apresentá-las em formato original.

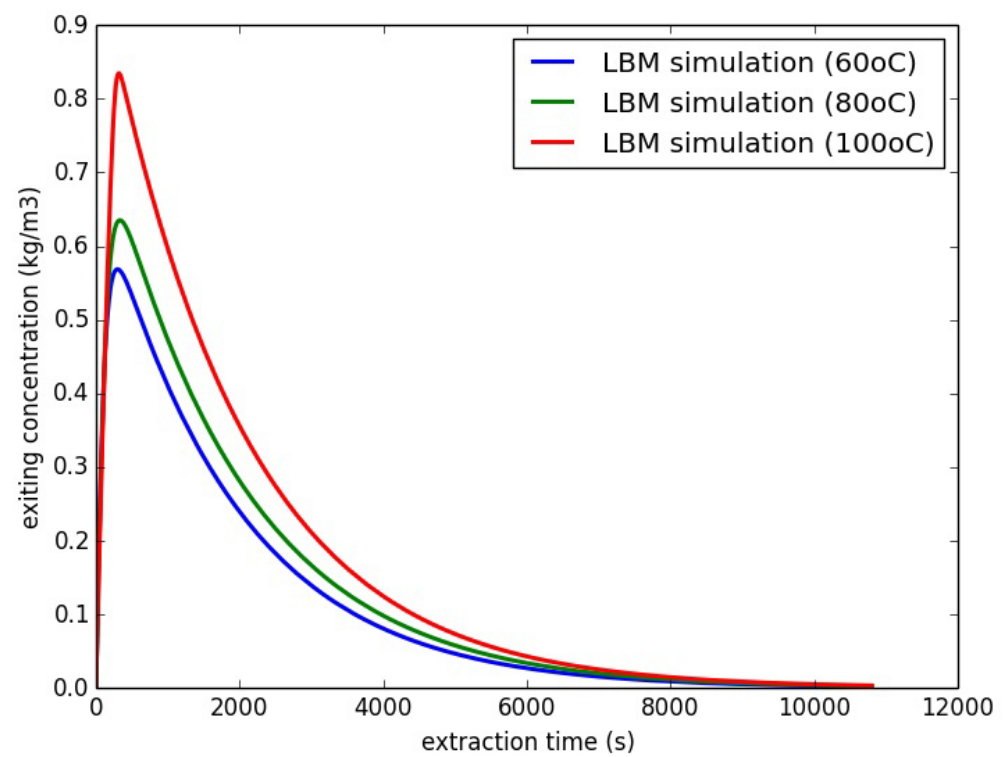

Figura 12. Extração de cafestol: curvas de concentração de extrato na fase fluida saindo do leito, simuladas via LBM.

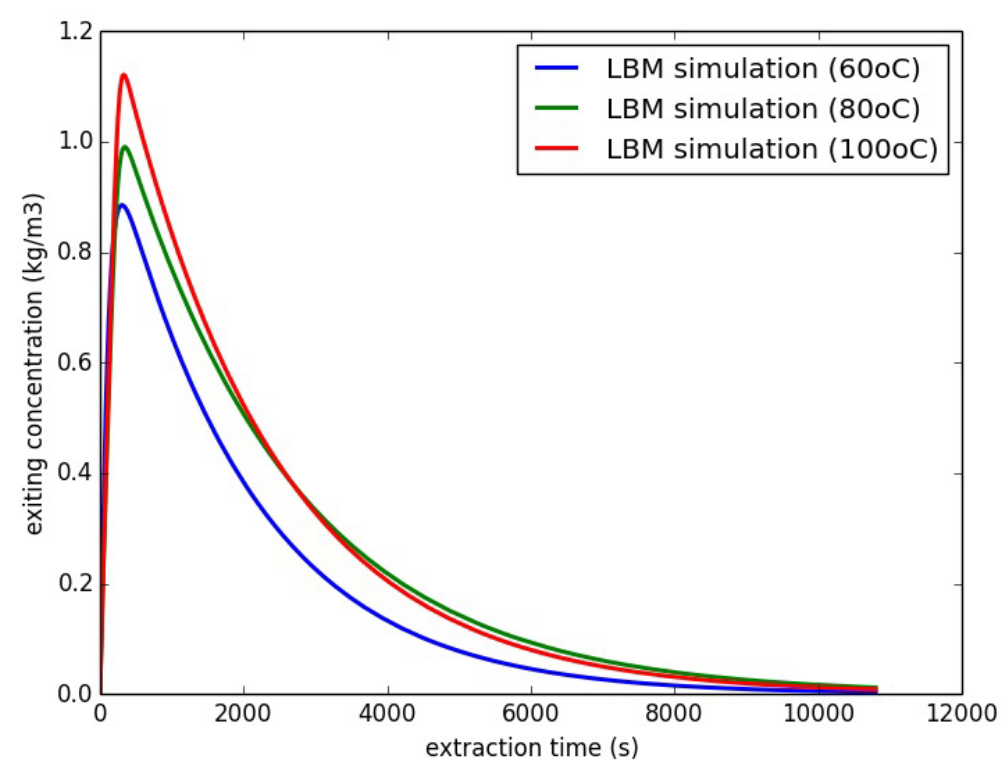

Figura 13. Extração de caveol: curvas de concentração de extrato na fase fluida saindo do leito, simuladas via LBM.

\subsubsection{Curvas de rendimento acumulado}

As figuras (14) e (15) exibem as curvas de rendimento acumulado para as espécies químicas cafestol e caveol, respectivamente. Tais curvas são expressas em base 
mássica, isto é, $\mathrm{kg}$ de extrato/kg de amostra. Os resultados foram comparados com dados experimentais (BELANDRIA et al., 2014).

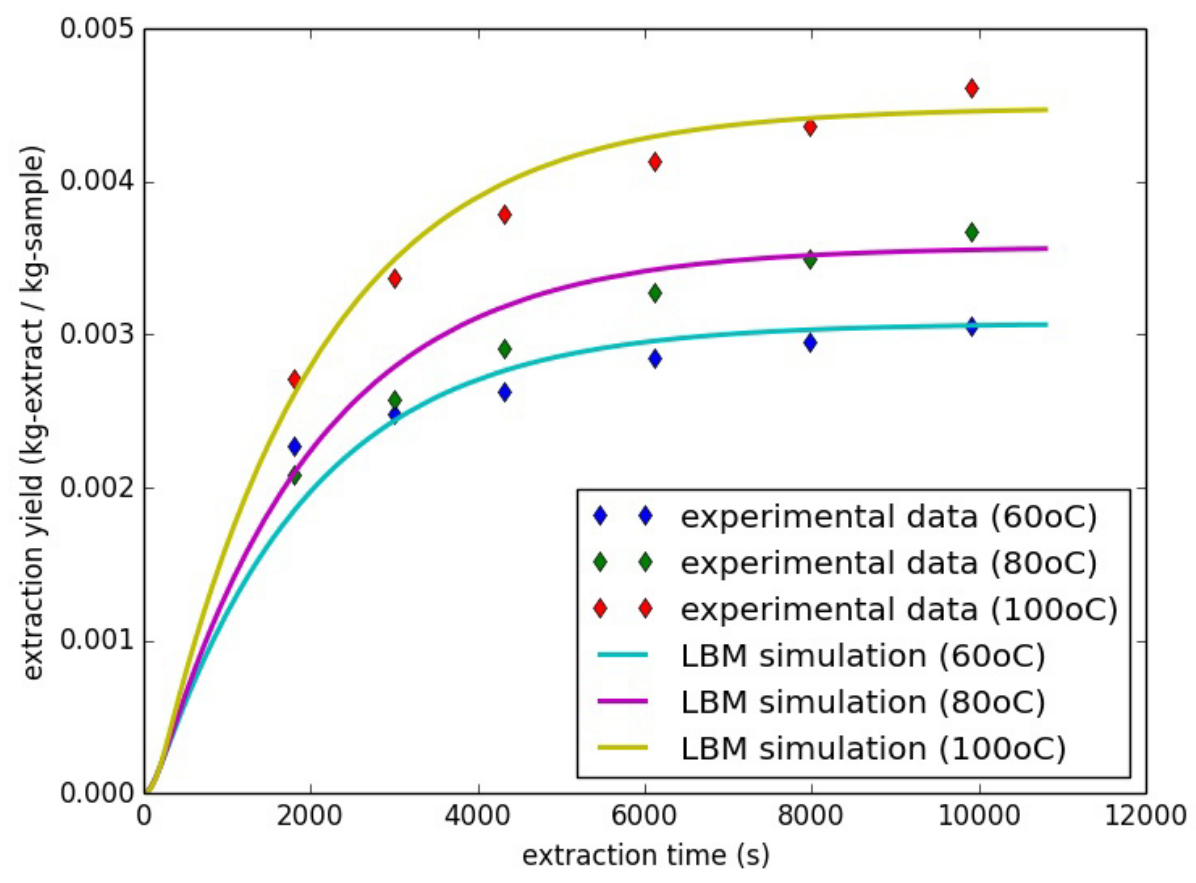

Figura 14. Extração de cafestol: comparação entre as curvas de rendimento simuladas via

LBM e os resultados experimentais.

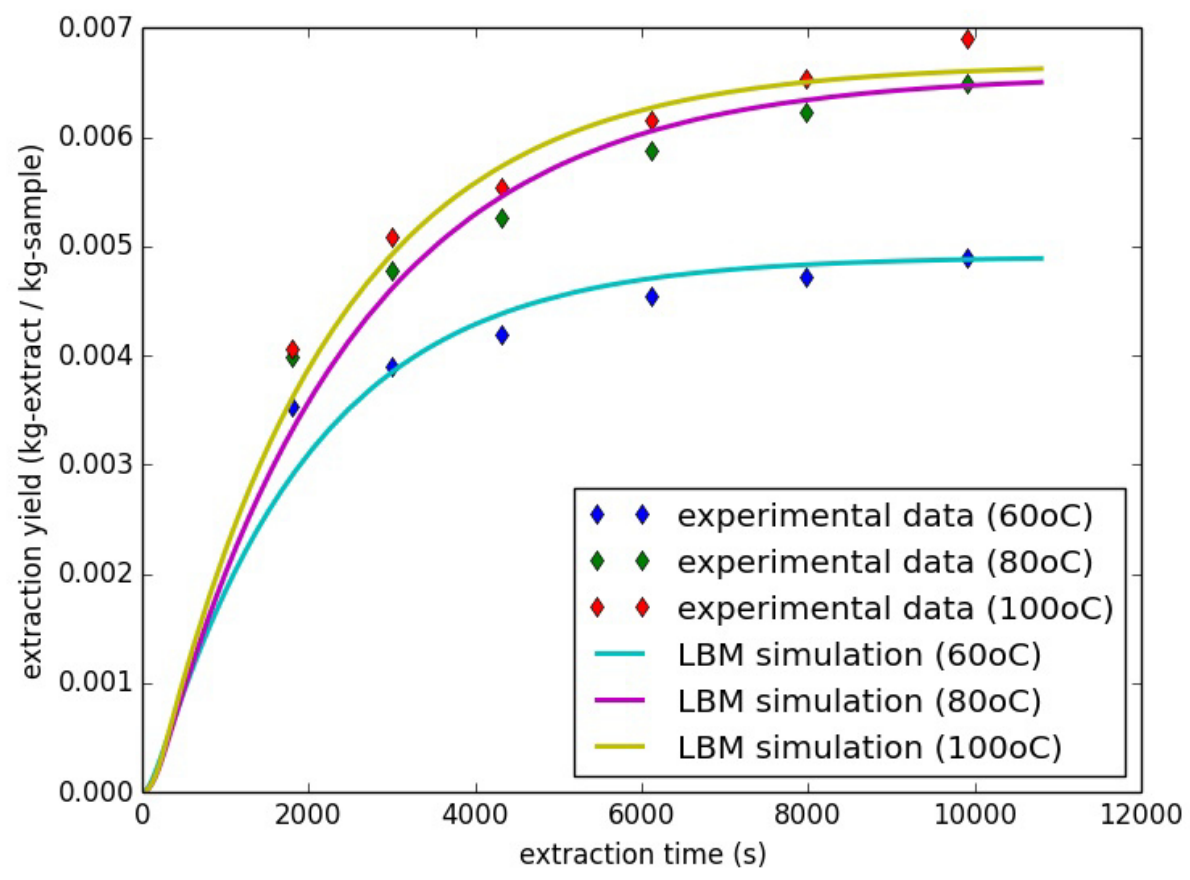

Figura 15. Extração de caveol: comparação entre as curvas de rendimento simuladas via LBM e os resultados experimentais. 


\subsubsection{Resultados parciais}

As curvas de concentração de extrato na fase fluida mostram a extração de uma grande quantidade de espécie química (cafestol e caveol) nos instantes iniciais. Tal comportamento é esperado em processos de extrações. As curvas de rendimentos também representaram o processo de extração das espécies químicas, com uso de fluido pressurizado. Os resultados foram comparados com dados experimentais do Laboratoire de Procédés, da Université d'Orléans, na França e mostram-se satisfatórios. Com exceção da extração da espécie química caveol, a temperatura de $100^{\circ} \mathrm{C}$ onde ocorreu o fenômeno de degradação térmica, como discutido em Rosa et al. (2014) e em Belandria et al. (2014).

\subsection{Análise de sensibilidade dos parâmetros}

Com intuito de analisar a sensibilidade de $D i, D$ e $k_{P}$ no processo de simulação via LBM, ao código computacional foi implementada uma interface gráfica para análise destes no processo. Inicialmente, escolheram-se valores de $D i, D$ e $k_{P}$ para representar o processo de extração de um dos compostos, mais especificamente a extração de cafestol a temperatura de $60^{\circ} \mathrm{C}$. O parâmetro a ser analisado variou numa faixa de valores pré definida, de modo que a simulação numérica representasse o processo de extração de espécies químicas a partir de matrizes vegetais. Enquanto os outros dois permaneceram fixos na varredura.

Ressalta-se que a análise supra no mecanismo de transferência de massa não é trivial. Contudo, neste trabalho buscou-se analisar a sensibilidade de cada parâmetro, especificamente nas simulações via LBM para uma dada espécie química.

\subsubsection{Difusividade intrapartícula}

A difusividade intrapartícula está presente nos mecanismos de transferência de massa sendo responsável pelo fenômeno de difusão na fase sólida. Para análise de sensibilidade, utilizou-se a cinética de extração da espécie química cafestol. Para tanto, a difusividade mássica axial e o coeficiente de partição volumétrica mantiveram-se fixos na varredura e assumiram os respectivos valores $4,30 \times 10^{-8} \mathrm{~m}^{2} / \mathrm{s}$ e $0,290 \mathrm{~m}^{3}$-sólidos $/ \mathrm{m}^{3}$-fluido. 


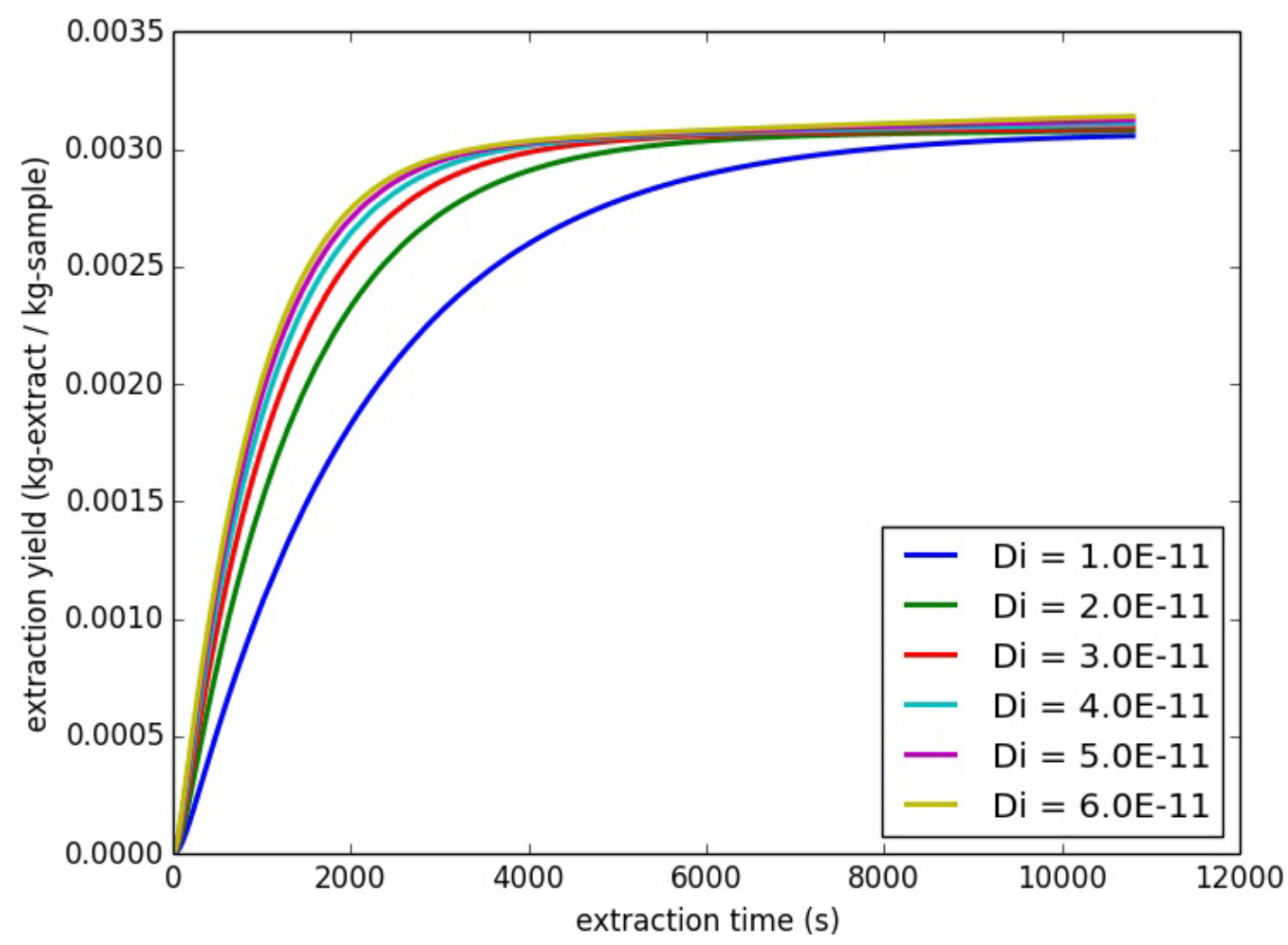

Figura 16. Análise de sensibilidade dos parâmetros: difusividade intrapartícula.

No intervalo de $1,0 \times 10^{-11} \mathrm{~m}^{2} / \mathrm{s} \leq D_{i} \leq 6,0 \times 10^{-11} \mathrm{~m}^{2} / \mathrm{s}$ para os valores de difusividade intrapartícula, a figura (16) exibe simulações de curvas de rendimento para extração de cafestol. Através da interface gráfica, observa-se que para maiores valores de difusividades intrapartícula atinge-se o platô (valor assintótico do rendimento) mais rapidamente. Este parâmetro não influenciou diretamente no rendimento da extração, pois as curvas de extração atingiram rendimentos bem próximos no final da simulação.

\subsubsection{Coeficiente de partição volumétrica}

Neste modelo, o coeficiente de partição volumétrica relaciona a transferência de massa entre a fase sólida e fluida, na condição de equilíbrio local. Para análise de sensibilidade utilizou-se a cinética de extração do cafestol. A difusividade intrapartícula e difusividade mássica axial mantiveram-se fixas na varredura e assumiram os respectivos valores $1.20 \times 10^{-11} \mathrm{~m}^{2} / \mathrm{s}$ e $4.30 \times 10^{-8} \mathrm{~m}^{2} / \mathrm{s}$. 


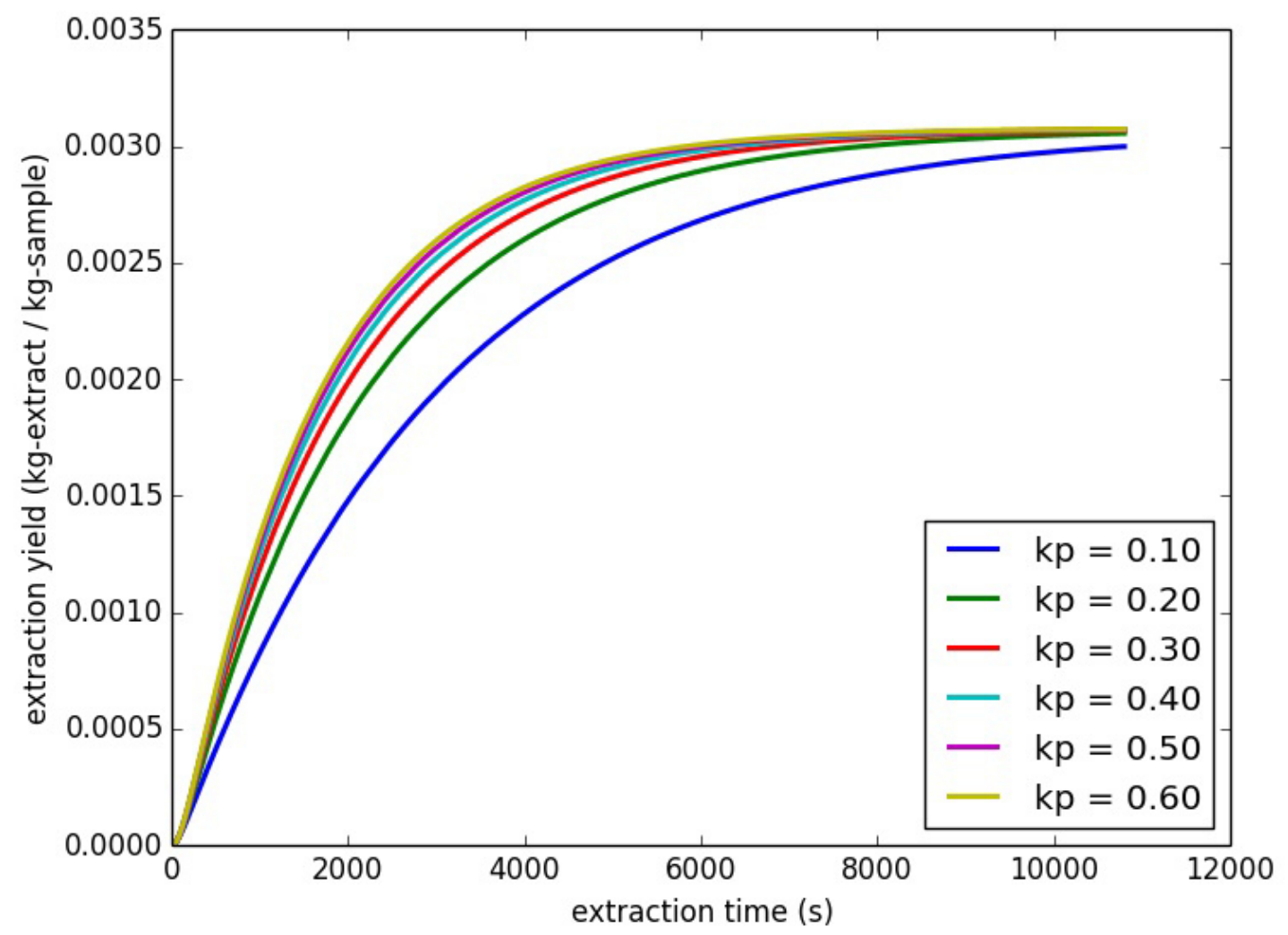

Figura 17. Análise de sensibilidade dos parâmetros: coeficiente de partição volumétrica.

No intervalo de $0,10 \mathrm{~m}^{3}$-sólidos $/ \mathrm{m}^{3}$-fluido $\leq k_{P} \leq 0,60 \mathrm{~m}^{3}$-sólidos $/ \mathrm{m}^{3}$-fluido para o coeficiente de partição volumétrica, a figura (17) exibe simulações de curvas de rendimento para extrações de cafestol. Com exceção da curva de rendimento com $k_{\mathrm{P}}$ extremo $(=0,10)$, as outras curvas atingiram rendimentos próximos do valor assintótico em tempos próximos entre si.

\subsubsection{Difusividade mássica axial}

No modelo adotado, a difusividade mássica axial está presente na fase fluida, em coexistência com o transporte convectivo. Por depender da velocidade intersticial, este último mecanismo é influenciado pela geometria e porosidade do leito. Para análise de sensibilidade utilizou-se a cinética de extração do cafestol. A difusividade intrapartícula e coeficiente de partição volumétrica mantiveram-se fixos na varredura e assumiram os respectivos valores $1,20 \times 10^{-11} \mathrm{~m}^{2} / \mathrm{s}$ e $0.290 \mathrm{~m}^{3}$-sólidos $/ \mathrm{m}^{3}$-fluido. 


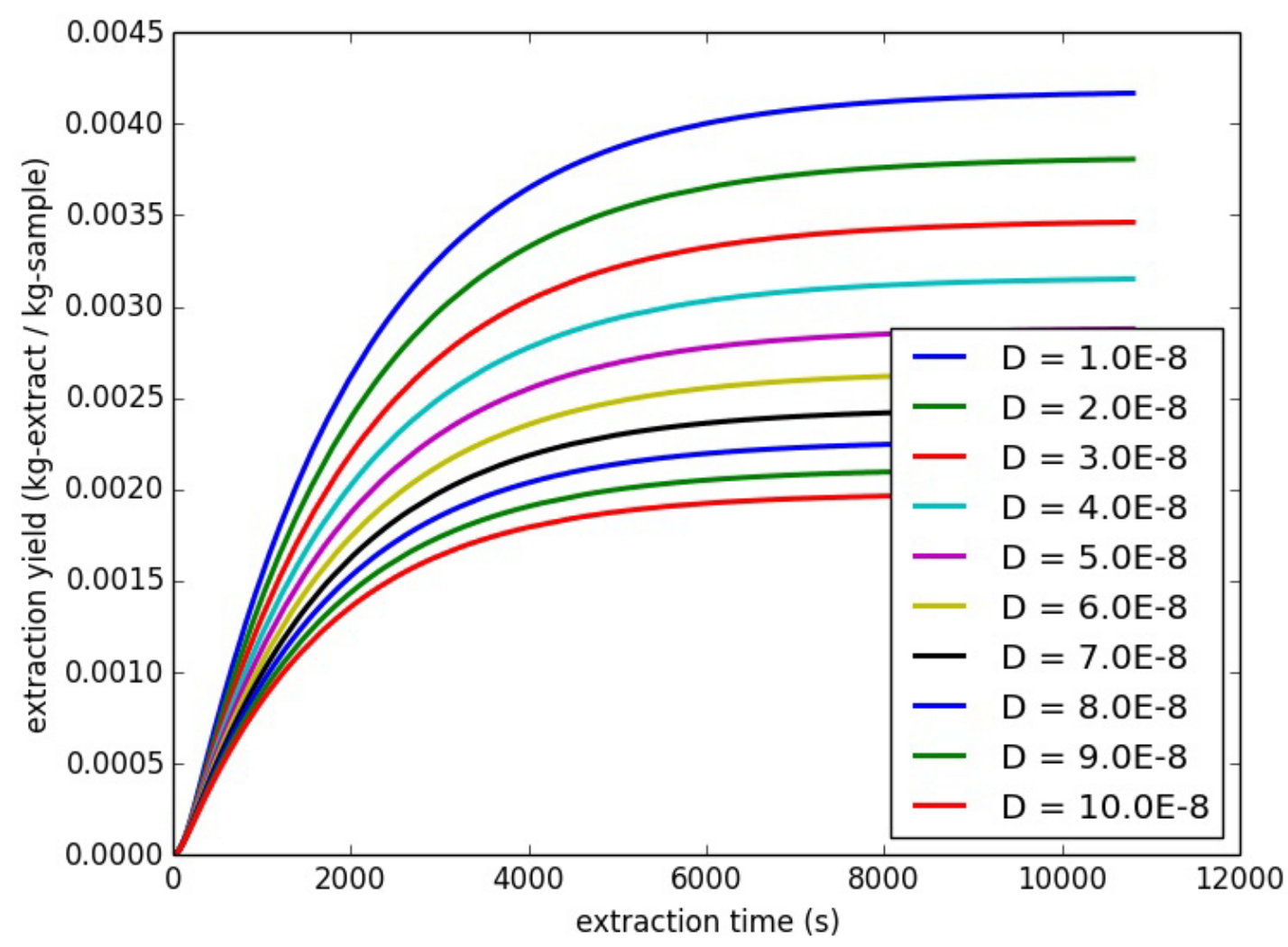

Figura 18. Análise de sensibilidade dos parâmetros: difusividade mássica axial.

No intervalo de $1,00 \times 10^{-8} \mathrm{~m}^{2} / \mathrm{s} \leq D \leq 10,0 \times 10^{-8} \mathrm{~m}^{2} / \mathrm{s}$ para a difusividade mássica axial, a figura 18 exibe simulações de curvas de rendimento para extração de cafestol. Observa-se que para maiores valores de difusividades axiais, o rendimento da extração é menor de modo que tal parâmetro influenciou significativamente as simulações via LBM. Ressalta-se que o modelo proposto é 1D (ou seja, sem incorporação da fluidodinâmica do processo); portanto, tal análise carece de futuras comparações com outros modelos em 2D (ou 3D), com descrição mais refinada do escoamento. 


\section{CONCLUSÕES}

Mesmo empregando-se um modelo dinâmico unidimensional (1a ordem com relação às coordenadas espaciais), a extração com fluido pressurizado requer a solução de equações diferenciais parciais (EDP) para as concentrações em fases distintas. Dentre as técnicas numéricas atualmente disponíveis, o método lattice Boltzmann (LBM) mostra-se adequado para a simulação de processos de extração. O presente trabalho partiu de um simulador LBM pré-existente para processos em leito fixo mas que não dispunha de rotinas de ajuste (otimização) de parâmetros nem de interface gráfica.

No sentido de introduzir melhorias ao simulador LBM original, a técnica do gradiente descendente foi devidamente implementada de modo que os valores obtidos de $D_{i}, D$ e kp foram ajustados com sucesso contra dados experimentais. Por sua vez, foi elaborada uma interface gráfica amigável para visualizar as curvas de rendimento de cada extração (cafestol e caveol).

Mediante a análise das simulações, verificou-se que o aumento da temperatura de extração das espécies químicas provocou o aumento da difusividade intrapartícula $\left(D_{i}\right)$ e do coeficiente de partição volumétrica $\left(k_{P}\right)$. Por outro lado, tal aumento acarretou a redução difusividade mássica axial $(D)$.

O simulador LBM é capaz de fornecer concentrações de extrato em qualquer posição do leito e em qualquer instante de tempo. As curvas de concentração na fase fluida simuladas junto à saída do leito indicaram a extração de grandes quantidades de extrato nos instantes iniciais do processo. Tal era o comportamento esperado, evidenciando assim a operacionalidade do simulador LBM.

Para a caracterização dos parâmetros de extração dos diterpenos de café verde, este trabalho aliou com sucesso o método lattice Boltzmann com base em um modelo 1D dinâmico à técnica do gradiente descendente para otimização (ajuste) em ambiente de programação Python. Além da sua viabilidade, tal combinação mostra-se promissora para simular processos de extração (ou similares) por se tratar de uma interface amigável e livre (não comercial), dispondo de bibliotecas computacionais adequadas.

Para trabalhos futuros sugere-se a extensão do modelo dinâmico para 2D (duas dimensões) ou 3D (três dimensões, com ou sem simetria axial). Para tanto, será necessário incorporar a fluidodinâmica no interior do leito, a qual requer a utilização da rede D2Q9. 
Adicionalmente, sugere-se a implementação da degradação térmica dos extratos junto com a respectiva cinética. 


\section{REFERÊNCIAS BIBLIOGRÁFICAS}

ASSOCIAÇÃO BRASILEIRA DA INDÚSTRIA DE CAFÉ (ABIC). O café no Brasil. Disponível em:<http://www.abic.com.br>. Acesso em: 07 abr. 2014.

AGRIANUAL: Anuário da Agricultura Brasileira. São Paulo: FN Consultoria \& Comércio, 2014.

São Paulo: FNP Consultoria \& Comércio, 2002.

AQUINO NETO, N. S.; RODRIGUES, A. B.; DA SILVA, M. G. Avaliação da confiabilidade em redes de distribuição radiais: calibração de parâmetros e estimação de incertezas associadas com índices de confiabilidade. In: CONGRESSO BRASILEIRO DE AUTOMÁTICA, 15., 2004, Gramado. Anais... Gramado: CBA, 2004. CD-ROM.

ARAÚJO, J. M. A.; SANDI, D. Extraction of coffee diterpenes and coffee oil using supercritical carbon dioxide. Food Chemistry, Oxford, v. 101, n. 3, p. 1087-1094, 2006.

ARUMUGA, P. D.; ANOOP, K. D. Lattice Boltzmann Simulation of Two- and ThreeDimensional Imcompressible Thermal Flows. Heat Transfer Engineering, India, v. 35, p. 1320-1333, 2014.

AZEVEDO, A. B. A.; KIECKBUSH, T. G.; TASHIMA, A. K.; MOHAMED, R. S.; MAZZAFERA, P.; VIEIRA DE MELO, S. A. S. Extraction of green coffee oil using supercritical carbon dioxide. The Journal of Supercritical Fluid, Amsterdam, v. 44, n. 1, p. 186-192, 2008.

BARBOSA, H. M. A.; MELO, M. M. R.; COIMBRA, M. A.; PASSOS, C. P.; SILVA, C. M. Optimization of the supercritical fluid coextraction of oil and diterpenes from spent coffee grounds using experimental design and response surface methodology. The Journal of Supercritical Fluids, Amsterdam, v. 85, p. 165-172, 2014.

BARROS, F.; DYKES, L.; AWIKA, J. M.; ROONEY, L. W. Accelerated solvent extraction of phenolic compounds from sorghum brans. Journal of Cereal Science, London, v. 58, p. 305-312, 2013.

BARTLE, K. D.; CLIFFORD, A. A.; HAWTHORNE, S. B.; LANGENFELD, J. J.; MILLER, D. J.; ROBINSON, R. A model for dynamic extraction using a supercritical fluid. The Journal of Supercritical Fluids, Amsterdam, v. 3, p. 143-149, 1990.

BELANDRIA, V.; OLIVEIRA, P. M. A.; CHARTIER, A.; OLIVEIRA, A. L.; BOSTYN, S. Quantitative extraction of cafestol and kawheol from green coffee using a pressurized 
fluid extraction approach. 2014. Submetido a Separation and Purification Technology.

BRASIL. MINISTÉRIO DA AGRICULTURA. Vegetal: estatísticas. Brasília, 2014. Disponível em: <http://www.agricultura.gov.br/vegetal/estatisticas>. Acesso em: 10 abr. 2014.

BROWN, R. E.; FRIMPONG, G.; LEE WILLIS, H. Failure rate modeling using equipment inspection data. IEEE Transactions on Power Systems, Piscataway, v. 19, p. 782-787, 2004.

BRUM, A. A. S.; DE ARRUDA, L. F.; REGITANO-D’ARCE, M. A. B. Métodos de extração e qualidade da fração lipídica de matérias-primas de origem vegetal e animal. Química Nova, São Paulo, v. 32, n. 4, p. 849-854, 2009.

BULLEY, N. R.; FATTORI, M.; MEISEN, A.; MOYLS, L. Supercritical fluid extraction of vegetable oil seeds. JAOCS, Heidelberg, v. 61, n. 8, p. 1362-1365, 1984.

BURIOL, T. M.; ARGENTA, M. A. Acelerando o desenvolvimento e o processamento de análises numéricas computacionais utilizando Python e CUDA. In: CONGRESSO IBERO LATINO AMERICANO DE MÉTODOS COMPUTACIONAIS EM ENGENHARIA, 30., 2009, Rio de Janeiro. Anais ... Rio de Janeiro: CILAMCE, 2009.

BUTT, M. S.; SULTAN, M. T. Coffee and its consumption: benefits and risks. Critical Reviews in Food Science and Nutrition, Philadelphia, v. 51, n. 4, p. 363-373, 2011.

CAMPANHA, F. G. Discriminação de espécies de café (Coffea arábica e Coffea canephora) pela composição de diterpenos. 2008. 91 f. Dissertação (Mestrado em Ciência de Alimentos) - Universidade Estadual de Londrina, Londrina. 2008.

CAMPOS, L. M. A. S.; MICHIELIN, E. M. Z.; DANIELSKI, L.; FERREIRA, S. R. S. Experimental data and modeling the supercritical fluid extraction of marigold (Calendula officinalis) oleoresin. The Journal of Supercritical Fluids, Amsterdam, v. 34, p. 163-170, 2005.

CASADA, M. E.; YOUNG, J. H. Model for hevolat and moisture transfer in arbitrarily shaped two-dimensional porous media. Transactions of the ASAE, St Joseph, v. 37, p. 1927-1938, 1994.

CASTILLO, M. L. R.; HERRAIZ, M.; BLANCH, G. P. Rapid analysis of holesterolelevating compounds in coffee brews by off-line high performance liquid chromatography / high resolution gas chromatography. Journal of Agricultural and Food Chemistry, Washington, v. 47, n. 4, p. 1525-1529, 1999. 
CAVIN, C.; HOLZHAEUSES, D.; SCHARF, G.; CONSTABLE, A.; HUBER, W. W.; SCHLTER, B. cafestol and kahweol, two coffee specific diterpenos with anticarcinogenic activity, Food and Chemical Toxicology, Kidlington, v. 40, p. 1155-1163, 2002.

CHARTIER, A.; BEAUMESNIL, M.; OLIVEIRA, A. L.; ELFAKIR, C.; BOSTYN, S. Optimization of the isolation and quantitation of kahweol and cafestol in green coffee oil. Talanta, v. 117, p. 102-111, 2013.

CHEN, S.; DOOLEN, G. D. Lattice Boltzmann Method for Fluid Flows. Annual Review of Fluid Mechanics, Palo Alto, v. 30, p. 329-364, 1998.

CHOPARD, B.; DUPUIS, A.; MASSELOT, A.; LUTHI, P. Cellular automata and lattice boltzmann techniques: an approach to model and simulate complex systems. Advances in Complex Systems, Singapore, v. 5, n. 2, p. 103-246, 2002.

CHU, Y. F.; CHEN, Y.; BLACK, R. M.; BROWN, P. H.; LYLE, B. J.; LIU, R. H.; OUC, B. Type 2 diabetes-related bioactivities of coffee: assessment of antioxidant activity, NFkB inhibition, and stimulation of glucose uptake. Food Chemistry, Amsterdam, v. 124, p. 914-920, 2011.

CLAUDE, B.; MORIN, P.; LAFOSSE, M.; BELMONT, A. S.; HAUPT, K. Selective solid-phase extraction of a triterpene acid from a plant extract by molecularly imprinted polymer. Talanta, Amsterdam, v. 75, p. 344-350, 2008.

COLLARES, M. M. Um resolvedor numérico baseado no método de lattice-boltzmann aplicado em unidades de processamento gráfico. 2012. 109 f. Dissertação (Mestrado) Instituto Militar de Engenharia, Rio de Janeiro, 2012.

CORRÊA, N. C. F.; ARAÚJO, M. E.; MACHADO, N. T.; FRANÇA, L. F. Mass transfer modeling supercritical extraction from solid material. In: INTERNATIONAL MEETING ON HIGH PRESSURE CHEMICAL ENGINEERING, 2., 2001, Hamburg. Proceedings... Hamburg, 2001. CD-ROM.

D’AMELIO, N.; DE ANGELIS, E.; NAVARINI, L.; SCHIEVANO, E.; MAMMI, S. Green coffee oil analysis by high-resolution nuclear magnetic resonance spectroscopy. Talanta, Amsterdam, v.110, p.118-127, 2013.

DANH, L. T.; MAMMUCARI, R.; TRUONG, R.; FOSTER, N. Response surface method applied to supercritical carbon dioxide extraction of Vetiveria zizanioides essential oil. Chemical Engineering Journal, Amsterdam, v. 155, p. 617-626, 2009.

DE MELO, M. M. R.; BARBOSA, H. M. A.; PASSOS, C. P.; SILVA, C. M. Supercritical fluid extraction of spent coffee grounds: Measurement ofextraction curves, oil 
characterization and economic analysis. The Journal of Supercritical Fluids, Amsterdam, v. 86, p. 150-159, 2014.

DE VRIES, U.; VELTHUIS, H.; KOSTER, K. Baking ovens and products quality - a computer model. Food Science and Technology Today, London, v. 9, p. 232-234, 1995.

DEDECCA, D. M. Anatomia e desenvolvimento ontogenético de Coffea arábica L. var. Typica Cramer. Bragantia, Campinas, v. 16, p. 315-355, 1957.

DIAS, R. C. E. Diterpenos em café: desenvolvimento de metodologia para análise, avaliação em cafés torrados e em diferentes tecidos do fruto, e estudo da estabilidade com o processo de torra. 2009. 158 f. Tese (Doutorado) - Universidade Estadual de Londrina, Londrina, 2009.

DIAS, R. C. E.; CAMPANHA, F. G.; VIEIRA, L. G. E.; FERREIRA, L. P.; POT, D.; MARRACCINI, P.; BENASSI, M. T. Evaluation of kahweol and cafestol in coffee tissues and roasted coffee by a new high-performance liquid chromatography methodology. Journal of Agricultural and Food Chemistry, Washington, v. 58, n. 1, p. 88-93, 2010.

DODDS, E. D.; MCCOY, M. R.; GELDENHUYS, A.; REA, L. D.; KENNISH, J. A. Microscale recovery of total lipids from fish tissue by accelerated solvent extraction. JAOCS, Heidelberg, v. 81, n. 9, p. 835-840, 2004.

EMPRESA BRASILEIRA DE PESQUISA AGROPECUÁRIA (EMBRAPA). Embrapa café. Disponível em: <http://www22.sede.embrapa.br/cafe/outros/links.htm>. Acesso em: 07 abr. 2014.

ESQUIVEL, P.; JIMÉNEZ, V. M. Functional properties of coffee and coffee by products. Food Research International, Kidlington, v. 46, n. 2, p. 488-495, 2011.

FERREIRA, M. A. N. Calibração de dados para estudos de confiabilidade em redes de distribuição: modelagem da condição dos equipamentos e dos índices de continuidade nodais. 2010. 86 f. Dissertação (Mestrado) - Centro de Ciência e Tecnologia, Universidade Federal do Maranhão, São Luís, 2010.

FILIPPIS, F. M. Extração com CO2 supercrítico de óleos essenciais de hon-sho e hosho - experimentos e modelagem. 2001. 101 f. Dissertação (Mestrado) - Programa de Pós-Graduação em Engenharia Química, Universidade Federal do Rio Grande do Sul, Porto Alegre, 2001.

FOLSTAR, P. Lipids. In: CLARKE, R. J.; MACRAE, R. (Eds.). Coffee: chemistry. London: Elsevier Applied Science, 1985. chap. 6, p. 203-222. 
FORTUNA, A. O. Técnicas computacionais para dinâmica dos fluidos: conceitos básicos e aplicações. São Carlos: EdUSP, 2012.

FRANÇA, L. F.; MEIRELES, M. A. A. Modeling the extraction of carotene and lipids from pressed palm oil (Elaes guineensis) fibers using supercritical $\mathrm{CO}_{2}$. The Journal of Supercritical Fluids, Amsterdam, v. 18, p. 35-47, 2000.

GASPAR, F.; LU, T.; SANTOS, R.; AL-DURI, B. Modelling the extraction of essential oils with compressed carbon dioxide. The Journal of Supercritical Fluids, Amsterdam, v. 25, p. 247-260, 2003.

GASSENMEIER, T.; BUSCH, P.; HENSEN, H.; SEIPEL, W. Some aspects of refatting the skin, Cosmetics \& Toiletries, Carol Stream, v. 113, p. 89-92, 1998.

GIOVANNUCCI, E. Meta-analysis of coffee consumption and risk of colorectal cancer. American Journal of Epidemiology, Cary, v. 147, p. 1043-1052. 1998.

GOLBERT, D. R. Modelos de Lattice-boltzmann aplicados à simulação computacional do escoamento de fluidos incompressíveis. 2009. 119 f. Dissertação (Mestrado) Laboratório Nacional de Computação Científica, Petrópolis, 2009.

GONÇALVES, A. R. Otimização em ambientes dinâmicos com variáveis contínuas empregando algoritmos de estimação de distribuição. 2011. 112 f. Dissertação

(Mestrado) - Universidade Estadual de Campinas, Campinas, 2011.

GOTO, M.; SATO, M.; HIROSE, T.; Extraction of peppermint oil by supercritical carbon dioxide. Chemical Engineering Journal, Amsterdam, v. 26, p. 401-407, 1993.

GROLLIER, J. F.; PLESSIS, S. Use os coffee bean oil as a sun filter- L'oreal. Patent US n. PI 4793990, 17 jan. 1988.

GUERRERO, G.; SUÁREZ, M.; MORENO, G. Chemosystematic study of diterpenoids in green coffee beans. In: INTERNATIONAL SCIENTIFIC COLLOQUIUM ON COFFEE, 20., 2005, Paris. Proceedings... Paris, 2005. v. 20, p. 292-296.

HARWORTH, R. D.; JUBB, A. H.; McKENNA, J. Cafestol. Part I. Journal American Chemistry Society, Washington, p. 1983-1989, 1955.

HATZOLD, T. Coffee: emerging health effects and disease prevention. In: CHU, Y. F. (Ed.). Introduction. New York: John Wiley \& Sons, 2012. p. 1-20.

HUBER, W. W.; SCHARF, G.; ROSSMANITH, W.; PRUSTOMERSKY, S.; GRASLKRAUPP, B.; PETER, B.; TURESKY, R. J.; SCHULTE-HERMANN, R. The coffee components kahweol and cafestol induce $\gamma$-glutamylcysteine synthetase, the rate 
limiting enzyme of chemoprotective glutathione synthesis, in several organs of the rat. Archives of Toxicology, Heidelberg, v. 75, n. 11-12, p. 685-694, 2002.

JUDICE, S. F. P. P. Animação de fluidos via modelos do tipo Lattice Gas e Lattice Boltzmann. 2009. 127 f. Dissertação (Mestrado) - Laboratório Nacional de Computação Científica, Petropólis, 2009.

KEIDEL, A.; VON STETTEN, D.; RODRIGUES, C.; MÁGUAS, C.; HILDEBRANDT, P. Discrimination of green arabica and Robusta coffee beans by Raman spectroscopy. Journal of Agricultural and Food Chemistry, Washington, v. 58 p. 11187-11192, 2010.

KOMORI, F. S. Desenvolvimento de um simulador computacional de dinâmica de fluidos utilizando o método de Lattice Boltzmann. 2012. 87 f. Dissertação (Mestrado) Escola Politécnica, Universidade de São Paulo, São Paulo, 2012.

KANMAZ, E. O. Subcritical water extraction of phenolic compounds from flaxseed meal sticks using accelerated solvent extractor (ASE). European Food Research and Technology, Heidelberg, v. 238, p. 85-91, 2014.

KIM, H. G.; KIM, J. Y.; HWANG, Y. P.; LEE, K. J.; LEE, K. Y.; KIM, D. H.; KIM, D. H.; JEONG, H. G. The coffee diterpenes kahweol inhibits tumor necrosis factor-induced expression of cell adhesion molecules in human endothelial cells. Toxicology and Applied Pharmacology, Maryland Heights, v. 217, p. 332-341, 2006.

KRAUJALIS, P.; VENSKUTONIS, P. R.; PUKALSKAS, A.; KAZERNAVICIUTE, R. Accelerated solvent extraction of lipids from Amaranthus spp. seeds and characterization of their composition. LWT - Food Science and Technology, London, v. 54, p. 528-534, 2013.

KURZROCK, T.; SPEER, K. Identification of kahweol fatty acid esters in Arabica coffee by means of LC / MS. Journal of Separation Science, Weinheim, v. 24, p. 843-848, 2001.

LANDAU, L. D.; LIFSHITZ, E. M. Fluid Mechanics. 2nd ed. Oxford: Pergamon Press, 1982.

LEE, K. J.; CHOI, J. H.; JEONG, H. G. Hepatoprotective and antioxidant effects of the coffee diterpenes kahweol and cafestol on carbon tetrachloride-induced liver damage in mice. Food and Chemical Toxicology, Kidlington, v. 45, p. 2118-2125, 2007.

LEHMANN, G.; NEUNHOEFFER, O.; ROSELIUS, W.; VITZTHUM, O. Verfahren zun Schutz von autoxydablen Stoffen. Patent DE n. 1668236, 16 mar. 1972. 
LIMA, F. A.; VASCONCELOS, S. M. L.; ATAÍDE, T. R.; SANT’ANA, A. E. G.; OMENA, C. M. B.; MENEZES, M. E. S. Coffee and human health: a focus on the substances of the beverage related to cardiovascular disease. Revista Nutrição, Campinas, v. 23, n. 6, p.1063-1073, 2010.

LUCAS, S.; CALVO, M. P.; GARCÍA-SERNA, J.; PALENCIA, C.; COCERO, M. J. Two-parameter model for mass transfer processes between solid matrixes and supercritical fluids: analytical solution. The Journal of Supercritical Fluids, Amsterdam, v. 41, p. 257-266, 2007.

MALISKA, C. R. Transferência de calor e mecânica dos fluidos computacional. Rio de Janeiro: LTC, 1995.

MANZANO, J. A. N. G; OLIVEIRA, J. F. Algoritmos: lógica para desenvolvimentos de programação de computadores. São Paulo: Erica, 2010.

MARTÍNEZ, J.; ROSA, P. T. V.; MEIRELES, M. A. A. Extraction of clove and vetiver oils with supercritical carbon dioxide: modeling and simulation. The Open Chemical Engineering Journal, Bussum, v. 1, p. 1-7, 2007.

MCNAMARA, G.; ZANETTI, G. Use of the Boltzmann equation to simulate lattice-gas automata. Physical Review Letters, College Park, v. 61, p. 2332-35, 1988.

MARRONE, C.; POLETTO. M.; REVERCHON, E.; STASSI, A. Almond oil extraction by supercritical $\mathrm{CO}_{2}$ : experiments and modelling. Chemical Engineering Science, Kidlington, v. 53, n. 21, p. 3711-3718, 1998.

MATIELLO, J. B.; SANTINATO, R.; GARCIA, A. W. R.; ALMEIDA, S. R.; FERNANDES, D. R. Cultura do café no Brasil: novo manual de recomendações. Rio de Janeiro: MAPA/Procafé, 2005. 434 p.

MAUL, A. A. Fluidos supercríticos, situação atual e futuro da extração supercrítica. Biotecnologia Ciência \& Desenvolvimento, Uberlândia, n. 11, p. 42-46, 1999.

MELRELES, M. M. A.; ZAHEDI, G.; HATAMI, T. Mathematical modeling of supercritical fluid extraction for obtaining extracts from vetiver root. The Journal of Supercritical Fluids, Amsterdam, v. 59, p. 23-31, 2009.

MENDONZA, M.; MUNOZ, J. D. Three-dimensional lattice Boltzmann model for electrodynamics. Physical Review E, College Park, v. 82, p. 056708, 2010.

MESOMO, M. C.; SCHEER, A. P.; PEREZ, E.; NDIAYE, P. M.; CORAZZA, M. L. Ginger (Zingiber officinale R.) extracts obtained using supercritical $\mathrm{CO}_{2}$ and compressed 
propane: kinetics and antioxidant activity evaluation. The Journal of Supercritical Fluids, Amsterdam, v. 71, p. 102-109, 2012.

MICHIELIN, E. M. Z.; DANIELSKI, L.; FERREIRA. S. R. S.; HENSE, L. Avaliação das variáveis de processo no extrato supercrítico de cavalinha (Equisetum arvense). In: SIMPÓSIO LATINO AMERICANO DE CIÊNCIA DE ALIMENTOS, 5., 2001, Campinas. Resumos... Campinas, 2001. v. 1, p. 128.

MISHRA, S.; POONIA, H.; VERNEKAR, R. R.; DAS, A. K. Lattice Boltzmann method applied to radiative transport analysis in a planar participating medium. Heat Transfer Engineering, India, v. 35, p. 1267-1278, 2014.

MOHAMAD, A. A. Lattice Boltzmann method: fundamentals and engineering applications with computer codes. London: Springer Verlag, 2011.

MURIEL, P.; ARAUZ, J. Coffee and liver diseases. Fitoterapia, Amsterdam, v. 81, p. 297-305, 2010.

NAIUD, M. M.; SULOCHANAMMA, G.; SAMPATHU, S. R.; SRINIVAS, P. Studies on extraction and antioxidant potential of green coffee. Food Chemistry, Amsterdam, v. 107, p. 377-384, 2008.

NAIK, S. N.; LENTZ, H.; MAHESHWARI, R. C. Extraction of perfumes and flavours from plant materials with liquid carbon dioxide under liquid-vapor equilibrium conditions. Fluid Phase Equilibria, Amsterdam, v. 49, p. 115-124, 1989.

NATIONAL COFFEE ASSOCIATION (NCA). All about coffee. Disponível em: <http://www.ncausa.org>. Acesso em: 07 abr. 2014.

NGUYEN, K.; BARTON, P.; SPENCER, J. S. Supercritical carbon dioxide extraction of vanilla. The Journal of Supercritical Fluids, Amsterdam, v. 4, p. 40-46, 1991.

NIELD, D. A.; BEJAN, A. Convection in porous medium. New York: Springer, 1999.

NORTON, T.; SUN, D. W. An overview of CFD applications in the food industry. In: SUN, D. W. Computational fluid dynamics in food processing. Boca Raton: CRC Press, 2007. p. 1-41.

OIGMAN, S. S.; DE SOUZA, R. O.; DOS SANTOS, J. H. M.; HOVEL, A. M.; HAMERSKI, L.; REZENDE, C. M. Microwave-assisted methanolysis of green coffee oil. Food Chemistry, Amsterdam, v. 134, p. 999-1004, 2012.

OKIYAMA, D. C. G.; RABI, J. A. Lattice-Boltzmann simulation of transport phenomena in agroindustrial biosystems. In: KORA, A. B. (Ed.). Advances in computational 
modeling research: theory, developments and applications. New York: Nova Science Publishers, 2013. p. 79-104.

OLIVEIRA, L. S.; FRANCA, A. S.; CAMARGOS, R. R. S.; FERRAZ, V. P. Coffee oil as a potential feedstock for biodiesel production. Bioresource Technology, Amsterdam, v. 99, n. 8, p. 3244-3250, 2008.

OLIVEIRA, P. M. A. Óleo de grãos de café verde obtidos por extração supercrítica, extração com fluido pressurizado e comparação de sua composição com o óleo de café extraído pelos pequenos produtores do Estado de São Paulo - análise da concentração de compostos bioativos. 2013. 102 f. Dissertação (Mestrado) - Faculdade de Zootecnia e Engenharia de Alimentos, Universidade de São Paulo, Pirassununga, 2013.

PEDERSSETTI, M. M.; PALÚ, F.; DA SILVA, E. A.; ROHLING, J. H.; CARDOZO FILHO, L.; DARIVA, C. Extraction of canola seed (Brassica napus) oil using compressed propano and supercritical carbone dioxide. Journal of Food Engineering, London, v. 102, p. 189-196, 2011.

PIGHINELLI, A. L. M. T. Estudo da extração mecânica e da transesterificação etílica de óleos vegetais. 2010. 201 f. Dissertação (Mestrado) - Faculdade de Engenharia Agrícola, Universidade Estadual de Campinas, Campinas, 2010.

PIMENTA, C. J. et al. Avaliação fisico-química e de qualidade do café (Coffea arabica L.) submetido a diferentes tempos de espera para secagem. Revista Brasileira de Armazenamento, Viçosa, n. 10, p. 36-41, 2008. Especial café.

QIAN, Y. H.; D'HUMIÈRES, D.; LALLEMAND, P. Lattice BGK models for NavierStokes equation. Europhysics Letters, Les Ulis, v. 17, p. 479-484, 1992.

RABI, J. A.; MOHAMAD, A. A. Simulation of zero-order transport problems using lattice-Boltzmann method: imposition of periodic boundary conditions or suppression of streaming step. In: DISCRETE SIMULATION OF FLUIDS DYNAMICS, 17., 2008, Florianópolis. Proceedings... Florianópolis, 2008. p. 25.

RABI, J. A. Modelagem e simulação de processos agroindustriais: cromatografia por afinidade bioespecífica, extração com fluido supercrítico, resfriamento rápido de alimentos e concentração de ${ }^{222} \mathrm{Rn}$ para aproveitamento de fosfogesso. 2011. $111 \mathrm{f}$. Tese (Livre Docência) - Faculdade de Zootecnia e Engenharia de Alimentos, Universidade de São Paulo, Pirassununga, 2011.

RAI, A.; PUNASE, K. D.; MOHANTY, B.; BHARGAVA, R. Evaluation of models for supercritical fluid extraction. International Journal of Heat and Mass Transfer, Kidlington, v. 72, p. 274-287, 2014. 
REIS-VASCO, E. M. C.; COELHO, J. A. P.; PALAVRA, A. M. F.; MARRONE, C.; REVERCHON, E. Mathematical modelling and simulation of pennyroyal essential oil supercritical extraction. Chemical Engineering Science, Kidlington, v. 55, p. 2917-2922, 2000 .

REVERCHON, E. Mathematical modeling of supercritical extraction of sage oil. AIChE Journal, Hoboken, v. 42, p. 1765-1771, 1996.

REVERCHON, E.; MARRONE, C. Supercritical extraction of clove bud essential oil: isolation and mathematical modeling. Chemical Engineering Science, Kidlington, v. 52, p. 3421-3428, 1997.

RIBEIRO, J. S.; SALVA, T. J.; FERREIRA, M. M. C. Chemometric studies for quality control of processed brazilian coffees using drifts. Journal of Food Quality, Hoboken, v. 33, p. 212-227, 2010.

RICKETTS. M. L. et al. The cholesterol-raising factor from coffee beans, cafestol, as an agonist ligand for the farnesoid and pregnane x receptors. Molecular Endocrinology, Bethesda, v. 21, n. 7, p. 1603-1616, 2007.

RINCON, M. A. D. Fracionamento do óleo de café verde por destilação molecular. 2011. 167 f. Tese (Doutorado) - Faculdade de Engenharia Química, Universidade Estadual de Campinas, Campinas, 2011.

ROOS, B.; VAN DER WEG, G.; URGERT, R.; VAN DE BOVENKAMP, P.; CHARRIER, A.; KATAN, M. B. Levels of cafestol, kahweol, and related diterpenoids in wild species of the coffee plant Coffea. Journal of Agricultural and Food Chemistry, Washington, v. 45, n. 8, p. 3065-3069, 1997.

ROSA, R. H.; VON ATZINGEN, G. V.; BELANDRIA, V.; OLIVEIRA, A. L.; BOSTYN, S.; RABI, J. A. Diterpenes extraction from green coffee beans: dynamic one-dimensional modelling and lattice Boltzmann simulation. 2014. Submetido a Biosystem engineering.

ROTHMAN, D. H.; Zaleski, S. Lattice-gas cellular automata: simple models of complex hydrodynamics. Cambridge, UK: Cambridge University Press, 1997.

SANTOS, L. O. E. Desenvolvimento de modelos de gás em rede para escoamentos monofásicos e bifásicos. 2000. 159 f. Tese (Doutorado) - Departamento de Engenharia Mecânica, Universidade Federal de Santa Catarina, Florianópolis, 2000.

SCHARNHOP, H.; WINTERHALTER, P. Isolation of coffee diterpenes by means of high-speed countercurrent chromatography. Journal of Food Composition and Analysis, Maryland Heights, v. 22, n. 3, p. 233-237, 2009. 
SCHEPKE, C.; MAILLARD, N. Performance improvement of the parallel lattice boltzmann method through blocked data distributions. In: COMPUTER ARCHITECTURE AND HIGH PERFORMANCE COMPUTING, 19., 2007, Gramado. Proceedings... Gramado: SBAC-PAD, 2007. p. 24-24, 71-78.

SCHIOZER, D. Mecânica dos fluidos. Rio de Janeiro: Livros Técnicos e Científicos, 1996. $629 \mathrm{p}$.

SILVA, C. F.; MOURA, F. C.; MENDES, M. F.; PESSOA, F. L. P. Extraction of citronella (Cymbopogon nardus) essential oil using supercritical CO2: experimental data and mathematical modeling. Brazilian Journal of Chemical Engineering, São Paulo, v. 28, n. 2, p. 343-350, 2008.

SOLANA, R. R.; SALGADO, J. M.; DOMÍNGUEZ, J. M.; DIÉGUEZ, S. C. Characterization of fennel extracts and quantification of estragole: optimization and comparison of accelerated solvent extraction and Soxhlet techniques. Industrial Crops and Products, Amsterdam, v. 52, p. 528-536, 2014.

SOVOVÁ, H. Rate of the vegetable oil extraction with supercritical $\mathrm{CO}_{2}$ - I. modeling of extraction curves. Chemical Engineering Science, Kidlington, v. 49, p. 409-414, 1994.

SOXHLET, F. Die gewichtsanalytische bestimmung des milchtfettes. Polytechnisches Journal, Erlangen, v. 232, n. 5, p. 461-465, 1879.

SPEER, K.; KÖLLING-SPEER, I. The lipid fraction of the coffee bean. Brazilian Journal of Plant Physiology, Campinas, v. 18, p. 201-216, 2006.

SPILLER, M. A. The chemical components of coffee. In: SPILLER, G. A. (Ed.). Caffeine. Boca Raton: CRC Press, 1998. p. 97-161.

STEFFANI, E. Modelagem matemática do processo de extração supercrítica de óleo essencial de ho-sho (Cinnamomum camphora Nees \& Eberm var. linaloolifera Fujita) utilizando CO . 2003. 92 f. Tese (Doutorado) - Departamento de Engenharia Química de Alimentos, Universidade Federal de Santa Catarina, Florianópolis, 2003.

SUBRA, P.; CASTELLANI, S.; JESTIN, P.; AOUFI, A. Extraction of $\beta$-carotene with supercritical fluids, experiments and modeling. The Journal of Supercritical Fluids, Amsterdam, v. 12, p. 261-269, 1998.

SUCCI, S. Lattice Boltzmann equation: failure or success? Physica A: Statistical and Theoretical Physics, Amsterdam, v. 240, n. 1-2, p. 221- 228, 1997.

SUCCI, S. The Lattice Boltzmann equation for fluid dynamics and beyond. New York: Oxford University Press, 2001. 
SUTTER, L. E. D. N.; SILVA, M. F. F.; CASSEL, E. Extração supercrítica, uma nova tecnologia industrial. Ciência e Tecnologia de Alimentos, Campinas, v. 14, n. 3, p. 3-10, 1994.

TANGO, J. S. Utilização industrial do café e dos seus subprodutos. Boletim do Instituto de Tecnologia de Alimentos - ITAL, Campinas, n. 28, dez. 1971.

TRINDADE, M. S. Secagem de soja em camada espessa: modelagem matemática e simulação numérica. 2013. 109 f. Dissertação (Mestrado) - Departamento de Ciências Exatas e Engenharia, Universidade Regional do Noroeste do Estado do Rio Grande do Sul, Ijuí, 2013.

TRUGO, L. C. Analysis of coffee products. In: CABALLERO, B.; TRUGO, L. C.; FINGLAS, P. M. (Org.). Encyclopedia of food sciences and nutrition. 2. ed. London: Academic Press, 2003. v. 3, p. 1498-1506.

TSUKUI, A.; OIGMAN, S. S.; REZENDE, C. M. Óleo de grãos de café cru: diterpenos cafestol e caveol. Revista Virtual de Química, Niterói, v. 6, n. 1, p. 16-33, 2013.

TURATTI, J. M.; LUCCAS, V. Obtenção e utilização de óleo de café. Instituto de Tecnologia de Alimentos, Campinas, F- PT 01625, 2001.

URGERT, R.; VAN DER WEG, G.; KOSMEIJER-SCHUIL, T. G.; VAN DE BOVENKAMP, P.; HOVENIER, R.; KATAN, M. B. Levels of the cholesterol-elevating diterpenes cafestol and kahweol in various coffee brews. Journal of Agricultural and Food Chemistry, Washington, v. 43, n. 8, p. 2167-2172, 1995.

VAN DER SMAN, R. G. M. Simple model for estimating heat and mass transfer in regular shaped foods. Journal of Food Engineering, London, v. 60, p. 383-390, 2003.

VAN DER SMAN, R. G. M. Lattice Boltzmann simulation of microstructures. In: SABLANI, S. S.; RAHMAN, M. S.; DATTA, A. K.; MUJUMDAR, A. R. Food and bioprocess modeling techniques. Boca Raton: CRC Press, 2007.

VARGAS, R. M. F.; CASSEL, E.; GOMES, G. M. F.; LONGHI, L. G. S.; ATTISERAFINI, L.; ATTI-SANTOS, A. C. Supercritical extraction of carqueja essential oil: experiments and modeling. Brazilian Journal of Chemical Engineering, São Paulo, v. 23, p. 375-382, 2006.

VIGGEN, E. M. The Lattice Boltzmann method with application in acoustic. 2009. 108 f. Master's Thesis - Department of Physics - NTNU, Trondheim, 2009. 
VILLERMAUX, J. Chemical engineering approach to dynamic modeling of linear chromatography: a flexible method for representing complex phenomena from simple concepts. Journal of Chromatography, Amsterdam, v. 406, p. 11-26, 1987.

WAGEMAKER, T. A. L. Variabilidade do teor de óleo, de seu fator de proteção solar e de outros componentes da fração lipídica do gênero Coffea visando usos alternativos aos grãos. 2009. 95 f. Dissertação (Mestrado) - Instituto Agronômico, Campinas, 2009.

WANG, L.; SUN, D.W. Recent developments in numerical modelling of heating and cooling processes in the food industry - a review. Trends in Food Science and Technology, Kidlington, v. 14, p. 408-423, 2003.

WERMELINGER, T.; D'AMBROSIO, L.; KLOPPROGGE, B.; YERETZIAN, C. Quantification of the robusta fraction in a coffee blend via raman spectroscopy: proof of principle. Journal of Agricultural and Food Chemistry, Washington, v. 59, p. 9074 9079, 2011.

WOLF-GLADROW, D. A. Lattice-Gas cellular automata and Lattice Boltzmann models: an introduction. Berlin: Springer-Verlag, 2000.

ZACHI, J. M Simulação numérica de escoamentos de fluidos pelo método de elementos finitos baseado em volumes de controle em malhas não estruturadas. 2006. 157 f. Dissertação (Mestrado) - Departamento de Engenharia Mecânica, Universidade Estadual Paulista, Ilha Solteira, 2006. 